bioRxiv preprint doi: https://doi.org/10.1101/2022.02.22.481508; this version posted February 22, 2022. The copyright holder for this preprint

(which was not certified by peer review) is the author/funder. All rights reserved. No reuse allowed without permission.

\title{
Sonic hedgehog-dependent recruitment of GABAergic interneurons into the developing visual thalamus
}

Rachana Deven Somaiya ${ }^{1,2}$, Katelyn Stebbins ${ }^{1,2,3}$, Hehuang Xie ${ }^{4,5,6,7}$, A. Denise R. Garcia ${ }^{8,9}$, Michael A. Fox ${ }^{1,5,10,11^{*}}$

1. Center for Neurobiology Research, Fralin Biomedical Research Institute at Virginia Tech Carilion, Roanoke, Virginia, 24016, USA

2. Graduate Program in Translational Biology, Medicine, and Health, Virginia Tech, Blacksburg, Virginia, 24061, USA

3. Virginia Tech Carilion School of Medicine, Roanoke, 24016, USA

4. Fralin Life Sciences Institute at Virginia Tech, Blacksburg, VA, 24061, USA

5. School of Neuroscience, College of Science, Virginia Tech, Blacksburg, Virginia, 24061, USA

6. Genetics, Bioinformatics and Computational Biology Program, Virginia Tech, Blacksburg, VA 24061, USA

7. Department of Biomedical Sciences and Pathobiology, Virginia-Maryland College of Veterinary Medicine, Blacksburg, Virginia, 24061, USA

8. Department of Biology, Drexel University, Philadelphia, Pennsylvania, 19104, USA

9. Department of Neurobiology and Anatomy, Drexel University College of Medicine, Philadelphia, Pennsylvania, 19104, USA

10. Department of Biological Sciences, College of Science, Virginia Tech, Blacksburg, Virginia, 24061, USA

11. Department of Pediatrics, Virginia Tech Carilion School of Medicine, Roanoke, Virginia, 24016, USA

* Correspondence: mafox1@vt.edu

\section{Summary:}

Axons of retinal ganglion cells (RGCs) play critical roles in the development of inhibitory circuits in visual thalamus. We previously reported that RGC axons signal astrocytes to induce the expression of fibroblast growth factor 15 (FGF15), a motogen required for GABAergic interneuron migration into visual thalamus. However, how retinal axons induce thalamic astrocytes to generate Fgf15 and influence interneuron migration remains unknown. Here, we demonstrate that impairing RGC activity had no impact on interneuron recruitment into mouse visual thalamus. Instead, our data show that retinalderived sonic hedgehog $(\mathrm{SHH})$ is essential for interneuron recruitment. Specifically, we show that thalamus-projecting RGCs express $\mathrm{SHH}$ and thalamic astrocytes generate downstream components of SHH signaling. Deletion of RGC-derived SHH leads to a significant decrease in Fgf15 expression, as well as in the percentage of interneurons recruited into visual thalamus. Thus, our findings identify a morphogen-dependent neuron-astrocyte signaling mechanism essential for the migration of thalamic interneurons.

\section{Keywords}

lateral geniculate nucleus, sonic hedgehog, astrocytes, interneurons, retinal ganglion cells, fibroblast growth factors

\section{Acknowledgments}

This work was supported by National Institutes of Health grants EY021222 and EY030568 (M.A.F.). We are grateful to the members of the M.A.F. lab for scientific discussion and comments on the manuscript. We thank Dr. Stefanie Robel for providing Aldh1/1-EGFP mice, Dr. Steven W. Wang for providing Math5 R26 floxstop-TeNT mice. The authors also thank Dr. John Campbell for input on bioinformatics approaches.

\section{Author contributions}

Conceptualization, Methodology, Investigation, Formal Analysis, Writing - Original Draft, R.D.S.; Investigation, Formal Analysis, K.S.; Resources, A.D.R.G.; Formal Analysis, H.X.; Conceptualization, Methodology, Writing - Review \& Editing, Supervision, Funding Acquisition, M.A.F.

Declaration of interests: The authors declare no competing interests. 


\section{INTRODUCTION}

The retina receives light-derived signals from our visual environment and transmits those signals to several dozen regions of the brain via axons of retinal ganglion cells (RGCs). In rodents, one of the brain regions densely innervated by RGC axons is the visual thalamus, which includes three retinorecipient nuclei: the dorsal lateral geniculate nucleus (dLGN), the intergeniculate leaflet (IGL), and the ventral lateral geniculate nucleus (vLGN). Despite being adjacent, these nuclei have diverse roles in visual processing, with the dLGN being important for image-forming visual functions, and the vLGN and IGL contributing more to non-image-forming visual functions (such as visuomotor functions, circadian photoentrainment, and mood regulation) (Fratzl et al., 2021; Guido, 2018; Huang et al., 2019; Monavarfeshani et al., 2017; Salay and Huberman, 2021). Not surprisingly based on these diverse functions, the principal neurons and their connectivity differs greatly between dLGN and vLGN/IGL (Krahe et al., 2011; Sabbagh et al., 2018, 2021). In fact, while the most abundant neurons in dLGN are glutamatergic thalamocortical relay cells, most neurons in vLGN are GABAergic and appear to represent a heterogeneous group of cell types with distinct morphologies, projections, and functions (Ciftcioglu et al., 2020; Crombie and Busse, 2021; Harrington, 1997; Yuge et al., 2011).

Despite these differences, there are some similarities in the cell types of dLGN and vLGN, including the presence and distribution of local interneurons (Arcelli et al., 1997; Evangelio et al., 2018; Jaubert-Miazza et al., 2005). In fact, a shared mechanism appears to exist that contributes to the recruitment and integration of these GABAergic neurons into both dLGN and vLGN (Golding et al., 2014; Su et al., 2020). Specifically, the recruitment of migrating interneurons into the perinatal dLGN and vLGN requires the embryonic and neonatal innervation of these regions by RGC axons. Loss of such RGC axons compromises both the recruitment of interneurons into dLGN and vLGN and their appropriate spacing within these regions. Our previous work demonstrated that the migration of GABAergic interneurons is facilitated by fibroblast growth factor 15 (FGF15), whose expression by thalamic astrocytes is dependent on retinal inputs (Su et al., 2020). How exactly retinal axons instruct astrocytes to generate FGF15 and facilitate interneuron recruitment into visual thalamus remains unclear.

Here, we sought to determine the role of retinal activity and/or axon-derived factors in the FGF15-dependent interneuron migration into the developing visual thalamus. Our data shows that impairing the activity of RGCs by genetically expressing tetanus toxin disrupts eye-specific segregation in dLGN and causes visual deficits in mice; however, it failed to impact interneuron recruitment into visual thalamus. Instead, we discovered that retinal-derived sonic hedgehog $(\mathrm{SHH})$ is necessary for interneuron recruitment. Not only do RGCs express SHH in the perinatal retina, but also astrocytes in the developing visual thalamus express several downstream molecules involved in the canonical SHH signaling pathway, such as Ptch1, Smo, and Gli1. Conditional deletion of SHH from RGCs led to decrease in Fgf15 expression and deficits in interneuron migration into visual thalamus. Thus, our findings demonstrate a novel activity-independent and $\mathrm{SHH}$ dependent molecular mechanism for RGC axons to orchestrate thalamic interneuron migration.

\section{RESULTS}

\section{Sonic Hedgehog (SHH), but not retinal activity, is critical for interneuron recruitment into visual thalamus}

Using Math5 $\%$ mutant mice, which lack RGC inputs to visual thalamus (Figure 1A), we previously reported a significant reduction in the number of interneurons in visual thalamus (Su et al., 2020). Here, we demonstrate this loss using in situ hybridization (ISH) for Gad1 mRNA, which encodes for glutamic acid decarboxylase 67 (GAD67), an enzyme required for the production of GABA. This confirmed significant reduction in Gad1+ neurons in both dLGN and vLGN (Figures $1 \mathrm{~A}$ and 1B). It is important to highlight that the reduction in Gad1+ cells in Math5 ${ }^{-1}$ vLGN is less striking than in dLGN, since most Gad1+ cells in vLGN are principal projection cells and not local interneurons.

Although the expression of FGF15 in visual thalamus is dependent on retinal inputs (Su et al., 2020, Figure S2A), it remains unclear whether this is due to neuronal activity or developmentally regulated factors released by RGC axons. Here, we set out to distinguish between these possibilities. First, we tested whether retinal activity was necessary for the interneuron recruitment into visual thalamus. To impair neuronal activity from RGCs, we took advantage of a transgenic Cre-inducible system to express Tetanus toxin (TeNT) in RGCs (R26 floxstop-TeNT). TeNT is a protease that cleaves the vesicular SNARE Synaptobrevin2/VAMP2 (Syb2), which is required for the exocytosis of neurotransmitters (Link et al., 
1992; Schoch et al., 2001). We crossed mice carrying the R26 floxstop-TeNT allele with Calb2 ${ }^{\text {Cre }}$ mice, in which most, if not all, RGCs express Cre recombinase (Kerr et al., 2019; Sando et al., 2017; Zhang et al., 2008) and widespread expression of Cre occurs in the GCL of the retina as early as P0 (Figures 1D and S1A).

Studies that have employed R26floxstop-TeNT to block neural activity have confirmed the suppression of neurotransmitter release by observing a loss of Syb2 in Cre-expressing cells (Sando et al., 2017). However, retinal inputs account for only $5-10 \%$ of the total synapses onto a dLGN relay cell (Bickford et al., 2010; Van Horn et al., 2000; Sherman and Guillery, 2002), making it difficult to detect significant changes in just a small fraction of the synapses in visual thalamus. Therefore, we sought other approaches to confirm impaired retinogeniculate (RG) neuronal activity in $R 26^{\text {floxstop- }}$ $\mathrm{TeNT}^{\mathrm{N}}$ CCalb2 ${ }^{\mathrm{Cre}}$. RGC activity during perinatal development is critical for eye-specific segregation of retinal axons (Huberman et al., 2003; Pfeiffenberger et al., 2005), therefore, we assessed eye-specific RGC projections in R26 floxstop-TeNT;Calb2 ${ }^{\text {Cre }}$ mice. Retinal terminals were labeled by intraocular injection of different fluorescently conjugated CTB into each eye at P12P20. In R26 floxstop-TeNT;Calb2Cre mice, we observed a significant increase in the area occupied by inputs from both eyes, a hallmark of impaired activity-dependent RG refinement (Figures S1D and S1E). Blocking retinal activity in these mice should also significantly impact visual behaviors, therefore, we also tested responses to a "looming stimulus" (Koehler et al., 2019). When presented with dark looming stimuli, control mice displayed an escape response, running to a shelter within the arena. In contrast, R26 floxstop-TeNT;Calb2 Cre mutants had imapired escape responses, indicating deficits in their ability to identify visual stimuli (Figures S1B and S1C). Together, these sets of both results suggest that there is a significant impairment in glutamate release by retinal axons in $R 26^{f l o x s t o p-T e N T}$;Calb2 ${ }^{\text {Cre }}$ mice, confirming that this mutant line can be used to study the role of retinal activity in the developing brain.

Using riboprobes against Gad1, we performed ISH to detect changes in percentage of interneurons in the visual

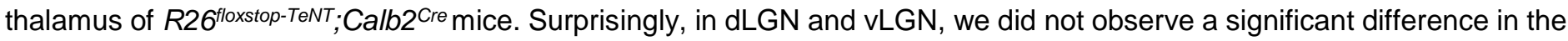
percentage of Gad1-expressing cells between the controls and mutants, revealing that retinal activity, or at least glutamate release by RGCs, had little impact on the recruitment of interneurons into visual thalamus (Figures 1D-1F).

Since retinal activity did not appear critical for interneuron recruitment into visual thalamus, we next investigated whether RGCs released factors beyond neurotransmitters, which could influence migration of thalamic interneurons. SHH signaling widely regulates FGF15 expression in the embryonic brain (Ishibashi and McMahon, 2002a; Martinez-Ferre et al., 2016; Saitsu et al., 2005) and RGCs have been reported to generate and secrete SHH (Dakubo et al., 2008; Peng et al., 2018a; Traiffort et al., 2001; Wallace and Raff, 1999), suggesting that SHH might regulate FGF15 expression and interneuron migration into visual thalamus. To test whether this was the case, we utilized a conditional allele of $S h h^{f / f l}$ and crossed it with $\mathrm{Nes}^{\mathrm{Cre}}$, in which there is early expression of Cre in neuronal and glial progenitors (Tronche et al., 1999) (Figure 1G). As previously reported, Shh ${ }^{f / f} \mathrm{Nes}^{\mathrm{Cre}}$ mutants survive gestation, however, die by P18 (Machold et al., 2003; Xu et al., 2005). In dLGN and vLGN of these mutants, we observed a significant and dramatic decrease in the percentage of Gad1-expressing interneurons (Figures $1 \mathrm{H}$ and 1I). Furthermore, loss of $\mathrm{SHH}$ signaling in $S h h^{f / / I I} N e s^{C r e}$ mice resulted in a reduction in Fgf15 expression, similar to what was observed in mice lacking retinal inputs (Figure S2). Thus, SHH signaling appears critical for both thalamic Fgf15 expression and the recruitment of interneurons into dLGN and vLGN.

\section{Astrocytic expression of SHH signaling components}

Activation of the SHH pathway is initiated when extracellular SHH binds to its canonical receptor, Patched-1 (PTCH1), present on target cells. This binding leads to the release of PTCH1-mediated inhibition of the membrane-spanning receptor, Smoothened (SMO), thereby allowing it to activate glioma-associated oncogene (GLI) transcription factors. Since our previous studies revealed that FGF15 is specifically generated by thalamic astrocytes during perinatal development (Su et al., 2020), we asked whether these astrocytes express components of the SHH signaling.

Using previously generated RNAseq datasets, we first assessed the expression profiles of several SHH signaling genes in the developing mouse dLGN and vLGN (Monavarfeshani et al., 2018). Analysis of this data showed that three canonical SHH signaling components, Ptch1, Smo, and Gli1, are expressed in visual thalamus at P3 (Figure 2A), when Fgf15 expression is high in this region (Su et al., 2020). To determine whether astrocytes express these components in visual thalamus, we undertook several approaches. First, we utilized $R 26^{t d T}$; Gli ${ }^{\text {CreER }}$ mice whereby tamoxifen administration leads to Cre-mediated recombination of the tdT fluorescent protein in Gli1-expressing cells (Hill et al., 2019). Thalamic slices from P7 R26 $6^{t d T}$;Gli1 CreER showed the presence of Gli1-tdT+ cells in both dLGN and vLGN (Figure 2B). Immunostaining for $S 100 B$, a commonly used marker for astrocytes, revealed $S 100 B$ expression in Gli1-tdT+ cells, suggesting that these 
astrocytes generate Gli1 (Figures $2 \mathrm{C}$ and 2D). However, we recently reported that $\mathrm{S} 100 \mathrm{BIHC}$ also labels a small population of microglia in visual thalamus (Somaiya et al., 2021), therefore, we confirmed that $t d T^{+}$cells were astrocytes by ISH for Gja1, the gene encoding Connexin 43. In fact, we observed that Gja1 mRNA was present in all Gli1-tdT+ cells, suggesting expression of this transcription factor was specific to astrocytes in visual thalamus (Figures $2 \mathrm{E}$ and $2 \mathrm{~F}$ ).

We next examined the expression of Ptch1 and Smo in thalamic astrocytes. For this, we perfomed ISH in Aldh1/1GFP mice in which most thalamic astrocytes are labelled with GFP (Somaiya et al., 2021). ISH with riboprobes against Ptch1 and Smo revealed that a high percentage of Aldh1/1-GFP+ astrocytes express these genes in P3 dLGN and vLGN (Figures 2G-2J). Together, these data demonstrate that astrocytes in perinatal visual thalamus have the cellular machinery to respond to $\mathrm{SHH}$.

\section{SHH is generated by RGCs in the developing perinatal retinas}

Several studies have shown that RGCs generate and release SHH (Dakubo et al., 2008; Peng et al., 2018a; Su et al., 2020; Traiffort et al., 2001; Wallace and Raff, 1999), therefore, we next asked whether they also express SHH at times corresponding to FGF15 expression in the visual thalamus. At P3, not only is Shh mRNA expression restricted to the GCL of the retina, but it is expressed by CALB2+ RGCs (Figure $3 A$ and $3 B$ ). Since at least 40 transcriptionally distinct types of RGCs exist in the mouse retina (Tran et al., 2019), we sought to identify whether all RGCs generate Shh mRNA (which looked to be the case based on ISH, Figure 3A) or whether specific RGC subtypes generate this morphogen in the perinatal retina. Rheaume et al. recently performed a comprehensive transcriptomic analysis of all mouse RGC subtypes at P5, therefore, we reanalyzed their publicly available single-cell RNAseq dataset to answer this question (Rheaume et al., 2018). Two important observations were made through this analysis: 1) All RGC subtypes express high levels of Calb2, confirming the reliability of targeting this molecule to study RGCs, 2) At least 38 out of 40 RGC subtypes express Shh mRNA (Figure $3 \mathrm{C})$. These results suggested that RGCs in the developing postnatal retina express $\mathrm{SHH}$, which can potentially influence the role of thalamic astrocytes.

\section{RGC-derived SHH is required for FGF15 expression and interneuron recruitment into visual thalamus}

To assess the role of RGC-derived SHH in the developing visual thalamus, we crossed our conditional allele Shht/fl with Calb2 ${ }^{\text {Cre }}$ mice (due to co-expression of Shh and Calb2 in RGC subtypes, Figure 3C). These mutants are viable, fertile, and indistinguishable from littermate controls. qRT-PCR analysis confirmed a significant decrease in Shh mRNA in the retina of these mutants (Figure 3D).

Based on this reduction, we investigated if RGC-derived $\mathrm{SHH}$ is necessary for FGF15 expression in the developing visual thalamus. ISH analysis demonstrated a significant reduction of $F g f 15^{+}$cells in the dLGN and vLGN of P3 $S h h^{f / f l i} ;$ Calb2 ${ }^{C r e}$ mutants (Figures $3 \mathrm{E}$ and $3 \mathrm{~F}$ ). These results resembled the reduced number of $\mathrm{Fgfl}^{+}$cells in both the Math5- visual thalamus and $\mathrm{Shh}^{f / f I} \mathrm{Nes}^{\mathrm{Cre}}$ visual thalamus. This suggests that RGC-derived $\mathrm{SHH}$ is not only necessary for astrocytic expression of Fgf15 in visual thalamus but that RGCs are the primary source of SHH to drive this thalamic Fgf15expression.

Given the importance of FGF15 from our studies, we subsequently examined the effect of loss of RGC-derived $\mathrm{SHH}$ on thalamic interneurons. We first assessed changes in interneuron recruitment after the first week of postnatal development, at the time when these cells have fully migrated into dLGN and vLGN (Su et al., 2020). Our ISH data revealed that there was significant reduction in the percentage of Gad1-expressing cells in dLGN and vLGN of Shht/fli;Calb2Cre mice at P7 (Figure 4A and 4B). It is possible, however, that the absence of RGC-derived SHH does not completely halt thalamic interneuron recruitment, but rather delays this migration process. Thus, we also investigated changes in the number of interneurons in adult $S h^{f / / t l}$;Calb2Cre mice. Indeed, our data revealed a persistent, significant decrease in the percentage of Gad1-expressing cells in dLGN and vLGN of adult mutants (Figure 4C and 4D), similar to what we have previously reported to occur in the visual thalamus of Fgf15 $\%$ mutants (Su et al., 2020). Overall, our findings highlight the dependence of astrocytic Fgf15 expression and recruitment of GABAergic interneurons into visual thalamus on the SHH signaling from retina.

\section{DISCUSSION}

The development of sensory neuronal circuits in many brain structures is coordinated by the arrival of sensory inputs, neuronal activity, and sensory experience (C. Brunjes, 1994; Katz and Shatz, 1996; Nithianantharajah and Hannan, 2006; Sanes and Lichtman, 2001). Here, we focused on the visual system where a growing body of evidence highlights 
critical roles for RGC axons and retinal activity in orchestrating thalamic development (Brooks et al., 2013; Charalambakis et al., 2019; Golding et al., 2014; Grant et al., 2016; He et al., 2019; Sabbagh et al., 2018; Seabrook et al., 2013). As one example, we previously reported that the retinal inputs signal through thalamic astrocytes to facilitate the recruitment of interneurons into dLGN and vLGN (Su et al., 2020). Specifically, thalamic astrocytes generate the motogen FGF15, which in contrast to other FGFs has reduced heparin-binding affinity (Ornitz and Itoh, 2015) making it an ideal guidance cue for long-distance migration of interneurons (Golding et al., 2014; Jager et al., 2016, 2021). In this study, we uncovered the molecular mechanism by which RGC axons signal to thalamic astrocytes to influence FGF15 expression. We show that this process is independent of RGC activity, but reliant upon SHH derived from the retina. The results highlight a SHH-dependent axo-glial-neuronal signaling mechanism important for thalamic development.

\section{SHH as an intermediary between RGCs and thalamic astrocytes for interneuron migration}

$\mathrm{SHH}$ signaling has well established roles in regulating morphogenesis, cell differentiation, and cell proliferation (Garcia et al., 2018; Ishibashi and McMahon, 2002b; Komada et al., 2008a; Marigo et al., 1996). In the embryonic retina, local expression of SHH is critical for promoting and maintaining the proliferation of retinal precursor cells (Jensen and Wallace, 1997; Wang et al., 2005). However, here we observed that Shh expression is largely confined to RGCs at perinatal ages. RGC-derived SHH protein has been shown to be anterogradely transported along axons, where it maintains the proliferative capacity of astrocytes in the optic nerve (Dakubo et al., 2008; Wallace and Raff, 1999) and acts as cue to guide eye-specific axon segregation at the optic chiasm (Peng et al., 2018b). Radiolabeling experiments have reported the presence of retina-derived $\mathrm{SHH}$ as far as the superior colliculus (Traiffort et al., 2001), a midbrain retinorecipient region, suggesting previously unexplored roles for RGC-derived SHH likely exist beyond the optic nerve and chiasm.

In the current study, we discovered that retinal-derived SHH plays important roles in the recruitment of interneurons into visual thalamus, a major RGC target site in the brain. These results are in line with several recent studies with showing that neuron-derived SHH directly acts on astrocytes residing in the target regions of their axonal projections (Garcia et al., 2010; Hill et al., 2019). We show that astrocytes in visual thalamus generate several downstream components of SHH signaling and that RGC-derived SHH is critical for astrocytic Fgf15 expression in visual thalamus. While FGF15 expression has been shown to be dependent on local SHH signaling in the embryonic brain (Ishibashi and McMahon, 2002b; Kim et al., 2018; Komada et al., 2008b; Saitsu et al., 2005; Yabut et al., 2019), this is the first study to provide evidence for longdistance SHH signaling to regulate the expression of astrocyte-derived FGF15.

The loss of astrocyte-derived FGF15 in Shh ${ }^{f / / 1 /} ; \mathrm{Calb2}{ }^{\mathrm{Cre}}$ mutants results in a significant loss of Gad1+ interneurons in both dLGN and vLGN. However, it does not result in an absence of these GABAergic neurons. In other brain regions, the loss of SHH signaling has been observed to dramatically affect specific subtypes of GABAergic neurons, such as interneurons that express parvalbumin (Pvalb) or Somatostatin (Sst) (Ihrie et al., 2011; Xu et al., 2005), which may explain the partial loss of $\mathrm{Gad1} 1^{+}$cells in the visual thalamus of $S h h^{f / f t} ;$ Calb2 ${ }^{C r e}$ mutants. In dLGN, transcriptional, morphological, and functional studies have been viable to parse interneurons into more than just one or two subtypes (Charalambakis et al., 2019; Leist et al., 2016), making it difficult to study the specificity for loss of Gad1+ cells in this retinorecipient brain region. In contrast, vLGN contains numerous transcriptionally distinct GABAergic cell types (including both local interneurons and projection neurons), some of which exhibit regional preferences, unique morphologies, and distinct connectivity (Fratzl et al., 2021; Sabbagh et al., 2021; Salay and Huberman, 2021). Thus, RGC-derived SHH may affect specific subtypes of GABAergic cells in vLGN. Unfortunately, we currently lack transcriptional or neurochemical markers to specifically label interneurons in vLGN (versus GABAergic projection neurons) making this challenging to address at this time.

It is also noteworthy that we observed more dramatic decrease in Gad1+ cells in Shh ${ }^{f / f l} ; \mathrm{Nes}^{\mathrm{Cre}}$ mutants, particularly in the vLGN, compared to the reduction observed in either Shht/fli Calb2 ${ }^{\mathrm{Cre}}$ or Math5 ${ }^{-/}$mice. We interpret this to indicate

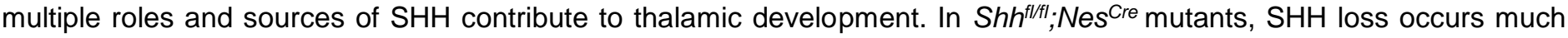
earlier in development and in progenitor zones (Lendahl et al., 1990; Zimmerman et al., 1994), likely impacting the generation of GABAergic progenitors that will eventually migrate into visual thalamus. Indeed, Shh null mice show defects in ventral patterning and a noticeable decrease in the size of their brain (Chiang et al., 1996; Machold et al., 2003; Rallu et al., 2002), indicating key roles for this morphogen in many aspects of early brain development. In Shht/fil;Calb2Cre mice, SHH is not lost from these progenitor zones, allowing us to differentiate between progenitor zone-derived SHH functions and RGC-derived SHH functions. An alternative possibility, however, is that $\mathrm{SHH}$ is also generated by cells within visual thalamus, which could also potentially influence interneuron migration process. While we detect no to very low expression 
of Shh in neonatal visual thalamus with microarray and sequencing techniques, this could reflect technical limitation in these approaches or analysis at the wrong ages (Monavarfeshani et al., 2018; Su et al., 2011).

\section{SHH signaling in astrocytes}

While SHH signaling is well-characterized for its dynamic roles in neural precursor cells and oligodendrocytes (Belgacem et al., 2016), much less is known about its function in astrocyte development, particularly in the context of the developing visual system. In the optic nerve, SHH has been reported to be necessary for maintenance of astrocyte proliferation (Dakubo et al., 2008; Wallace and Raff, 1999). Our work demonstrates that this signaling pathway is also critical for the expression of Fgf15 by thalamic astrocytes. However, only a small fraction of astrocytes express Fgf15 in visual thalamus (Su et al., 2020), raising the questions of whether only some thalamic astrocytes generate the machinery to respond to $\mathrm{SHH}$ or whether retina-derived $\mathrm{SHH}$ itself can alter the identity of thalamic astrocytes to generate heterogeneity in these cells. In support of the latter possibility, neuron-derived SHH is integral for maintaining the identity of Bergmann glial cells, a specialized astrocyte type in the cerebellum (Farmer et al., 2016). However, it is important to note that we found that a much greater proportion of astrocytes in visual thalamus generate SHH signaling components, Ptch1 and Smo, compared to those that generate Fgf15. One possibility is that all thalamic astrocytes can generate SHH-induced Fgf15, but they do it asynchronously. The widespread expression of $\mathrm{SHH}$ signaling components in thalamic astrocytes also suggests that this pathway could be important in ways beyond interneuron migration. Outside of the thalamus, SHH appears to be important for a variety of astrocytic functions, including modulation of neuronal activity (Hill et al., 2019), regulation of energy metabolism (Tirou et al., 2021), and neuroprotection (Ugbode et al., 2017). These studies highlight the need to further explore the roles for $\mathrm{SHH}$ signaling in thalamic circuits.

\section{Neuronal activity from RGCs and thalamic interneuron migration}

Many developmental aspects underlying orderly connections in the mammalian visual system are dependent on retinal activity even before eye opening (D'Souza and Lang, 2020; Huberman et al., 2008). In the case of thalamic interneurons, the role of retinal activity in their migration, differentiation, or incorporation into thalamic circuits was unresolved prior to these studies. Application of tetrodotoxin in neonatal organotypic thalamic slices led to the suggestion that activity was necessary for directing the spatial incorporation of these interneurons into dLGN circuits (Golding et al., 2014). In the present study, we investigated whether in vivo RGC activity contributes to the initial recruitment of GABAergic interneurons into dLGN and vLGN. Our results revealed that retinal activity had little effect on the percentage of interneurons recruited into dLGN and vLGN. This suggests that GABAergic interneurons migrate into visual thalamus independently of RGC activity. Although this genetic approach to inhibit neuronal activity has been shown to be effective in the developing hippocampus (Sando et al., 2017), it is possible that we may not have completely blocked the release of neurotransmitters from RGCs in R26 floxstop-TeNT; Calb2 Cre mutants (because of incomplete expression of TeNT by all RGCs, developmentally regulated expression of TeNT or other confounding issues) and that the remaining activity was sufficient to directly influence the interneuron migration process. In fact, it is possible that retinal activity may even induce RGCs to release SHH. Although such roles of neuronal stimulation on SHH release have not been reported in visual thalamus, activity in hippocampal neurons has been shown to cause the release of SHH in a SNAREs- and $\mathrm{Ca}^{2+}$ - dependent manner (Su et al., 2017). We argue that is not the case based on the early and broad expression of Cre in the driver line applied here - ensuring all subtypes of RGCs will express TeNT at birth. Moreover, the impaired refinement of eye-specific RGC projections in $R 26^{\text {floxstop-TeNT; }}$ Calb2 ${ }^{\text {Cre }}$ mice similar to impairments induced by manipulation and blocking of retinal activity early in perinatal development (Huberman et al., 2003; Pfeiffenberger et al., 2005) suggests that activity is functionally reduced in these mutants. Thus, our data indicates interneuron recruitment into visual thalamus is not dependent on retinal activity, but on RGC-derived SHH. Overall, this suggests that retinal inputs have both activity-dependent and activity-independent roles in orchestrating the development of visual thalamus. The techniques typically used to study how retinal inputs impact the thalamic development, surgical or genetic removal of RGC axons from thalamus have failed to distinguish between these independent roles previously. 
A

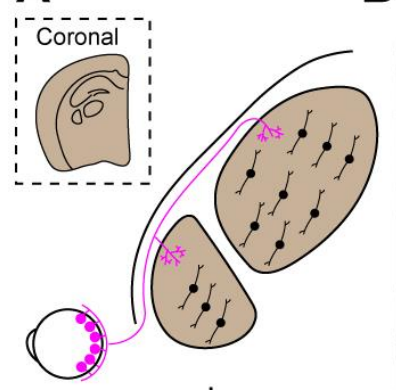

B
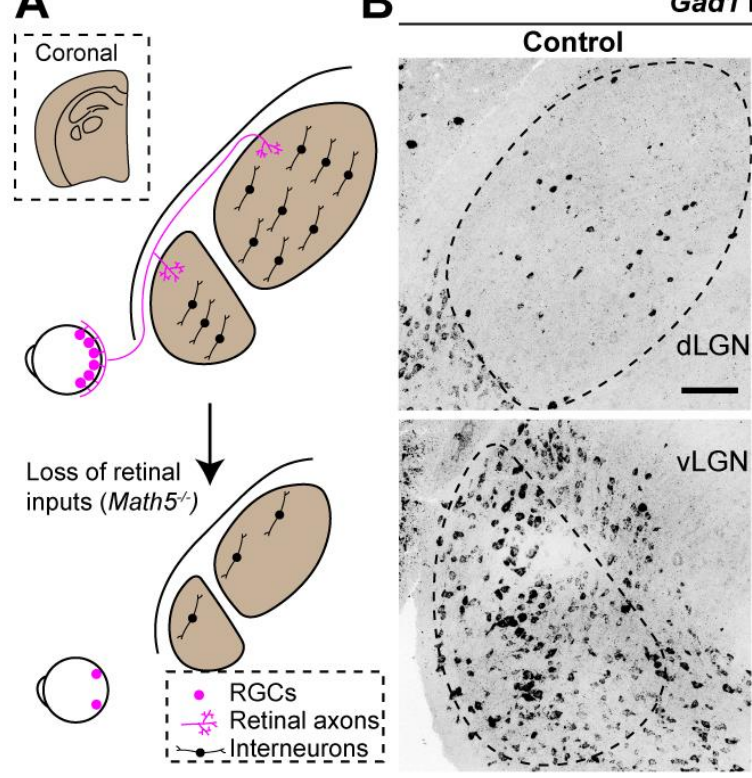

E
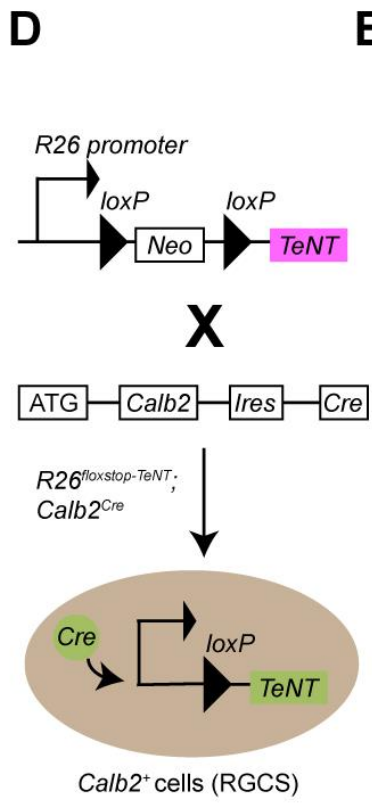

G

Shh gene:

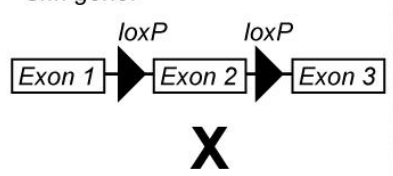

Nestin promoter \& enhancer
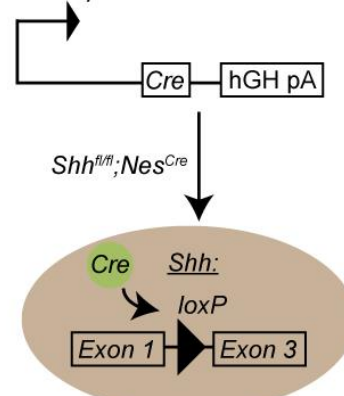

$\mathrm{Nes}^{+}$cells (neuronal and glial precursors )

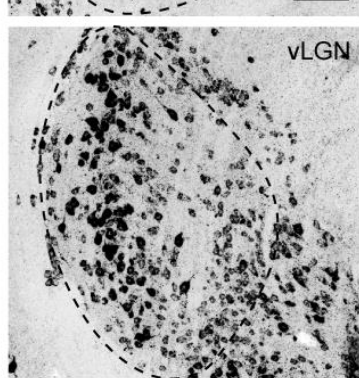

H

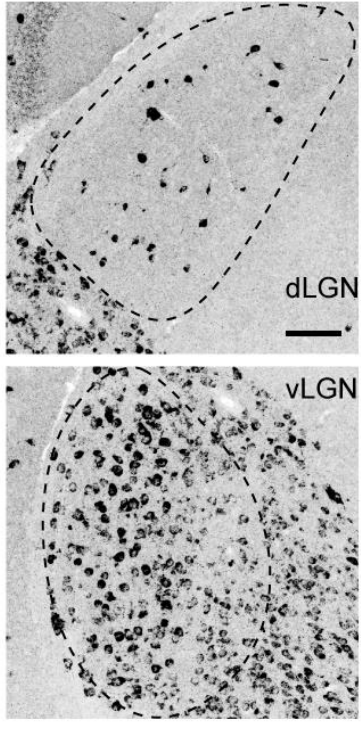

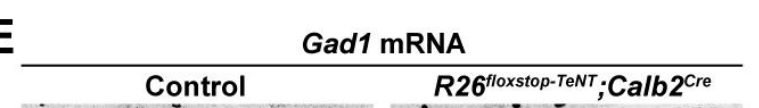
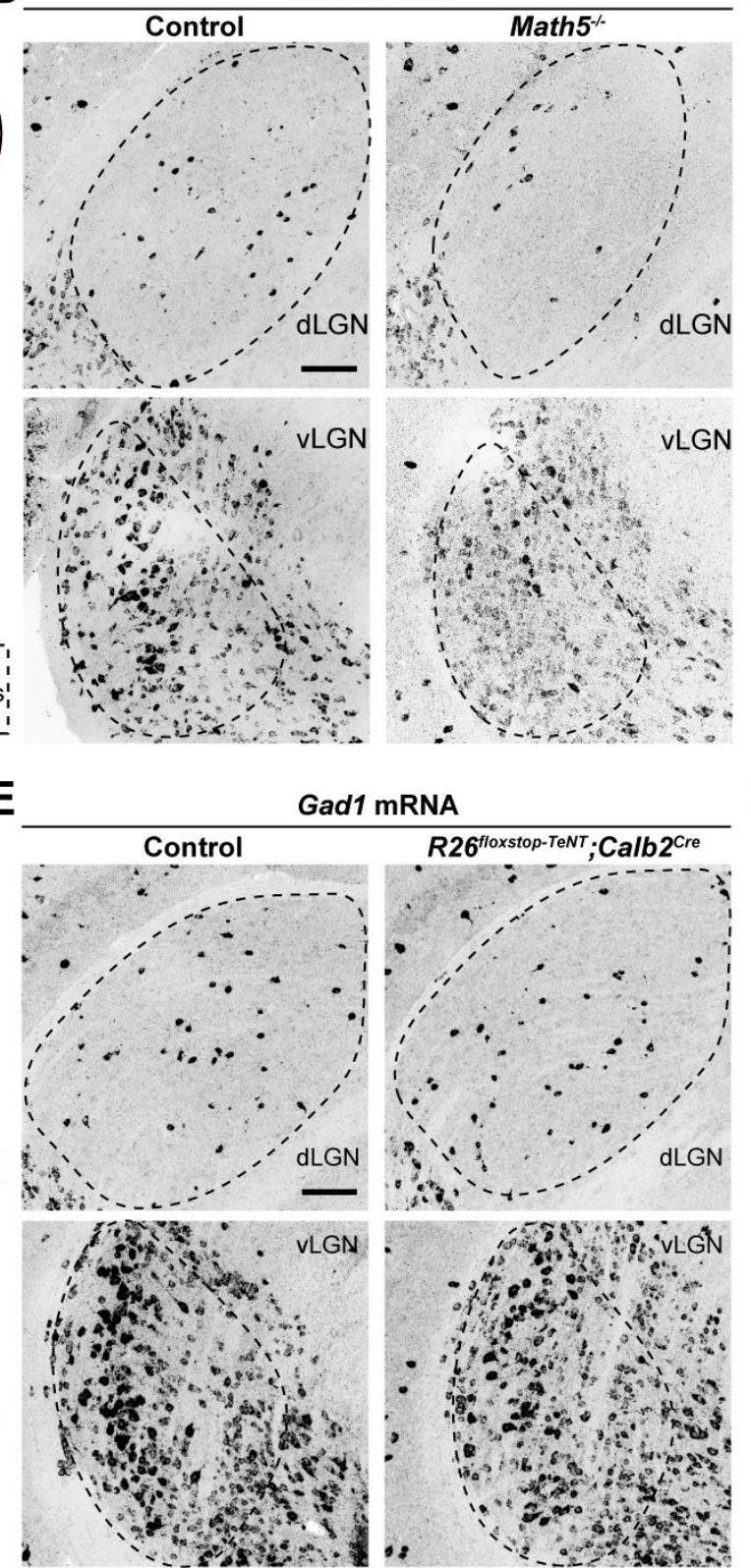

C $\square$ Control
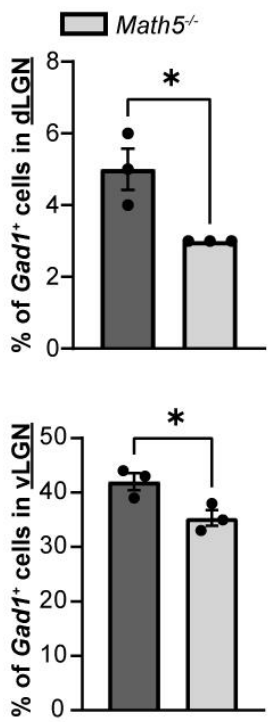

$F$
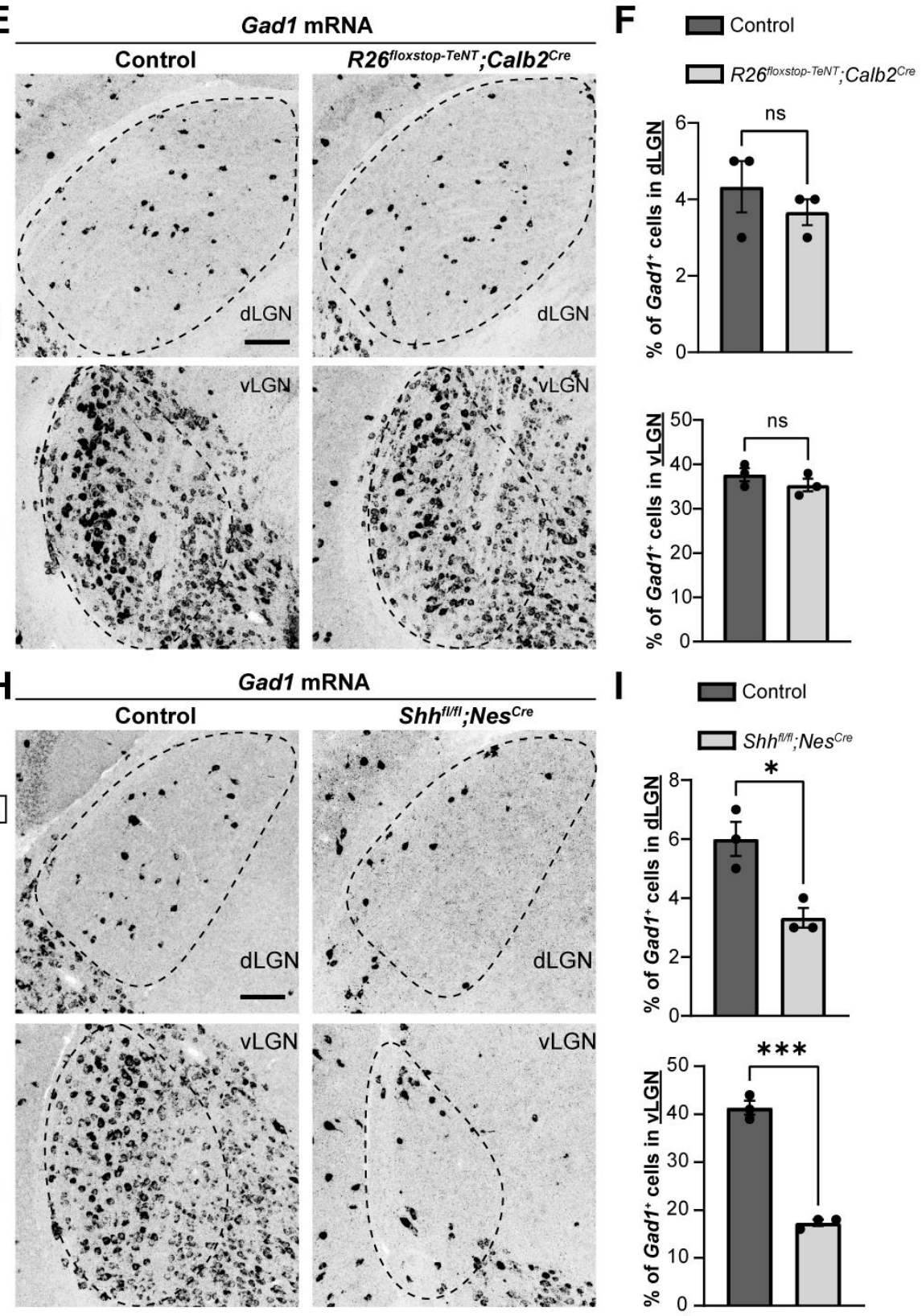
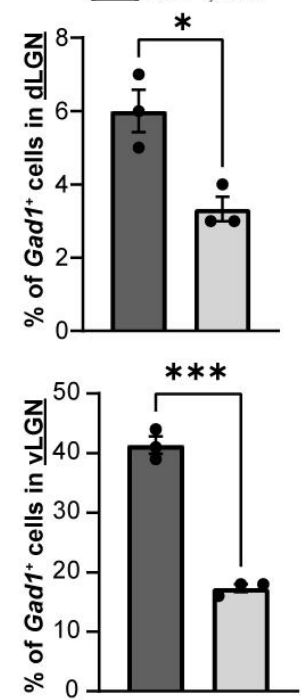
Figure 1. Sonic hedgehog, but not retinal activity, is required for the recruitment of interneurons into visual thalamus

(A) Schematic representation of loss of retinal inputs and interneurons in visual thalamus of Math5\% mice.

(B) ISH shows a reduction in Gad1+ cells in dLGN and vLGN of >P150 Math5 - mice compared with controls.

(C) Quantification of percentage of Gad1+ cells in dLGN and vLGN of $>\mathrm{P} 150$ controls and Math5 $\%$ mice. Each data point represents one biological replicate and bars depict means \pm SEM. Asterisks $\left({ }^{*}\right)$ indicate $P<0.05$ by Student's $t$-test $(n=3$ mice for each group).

(D) Schematic representation of Calb2 Cre-inducible expression of TeNT in RGCs. R26floxstop-TeNT mice with the construct containing a loxP-flanked neomycin (Neo) cassette and TeNT coding sequence under Rosa26 locus, were crossed with Calb2 ${ }^{\text {Cre }}$ mice that harbor a Cre recombinase and internal ribosome entry site (IRES) in the Calb2 locus.

(E) ISH for Gad1 in dLGN and vLGN of P120 control and R26 floxstop-TeNT; Calb2 ${ }^{\text {Cre }}$ mice.

(F) Quantification revealed no significant difference in Gad1+ cells in visual thalamus of control and R26floxstop-TeNT;Calb2Cre mice. Each data point represents one biological replicate and bars depict means \pm SEM. ns, indicates no significant differences by Student's $t$-test ( $n=3$ mice for each group).

(G) Schematic representation of strategy to delete SHH from neural cells in the developing brain. This was achieved by crossing Shht/fll mice, which have two loxP sites flanking exon 2 of the Shh gene, with Nescre transgenic mice that contain a Cre recombinase and human growth hormone polyadenylation signal (hGH pA) under the control of Nestin promoter and enhancer.

(H) ISH revealed a dramatic reduction in Gad1+ cells in dLGN and vLGN of P18 Shh $h^{f / f f} N e s^{C r e}$ mice compared with controls.

(I) Quantification of percentage of Gad1+ cells in dLGN and vLGN of P18 control and Shh $h^{\text {fl/filNes }}{ }^{\text {Cre }}$ mice. Each data point represents one biological replicate and bars depict means \pm SEM. Asterisks represent significant differences ${ }^{* * *} P<0.001$; ${ }^{*} P<0.05$ ) by Student's $t$-test ( $n=3$ mice for each group).

Scale bars in C, E, H: $100 \mu \mathrm{m}$. 
A

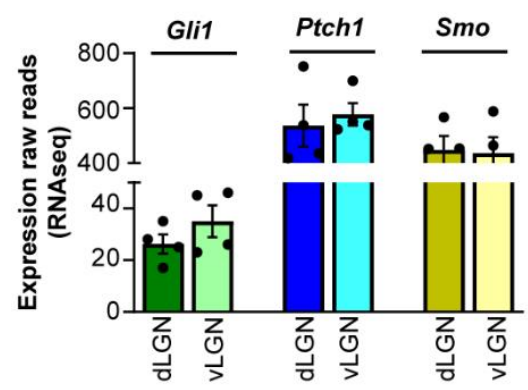

C

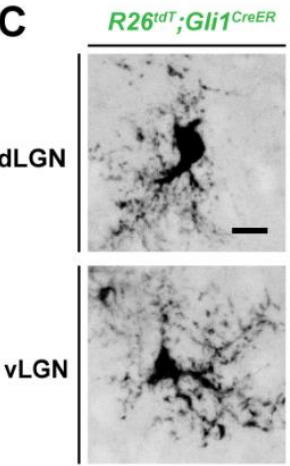

E $R 26^{t T} ;$ Glii CreeR
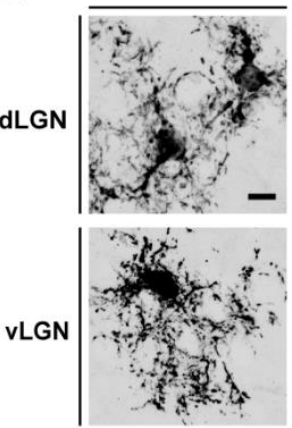

G Ptch1 mRNA

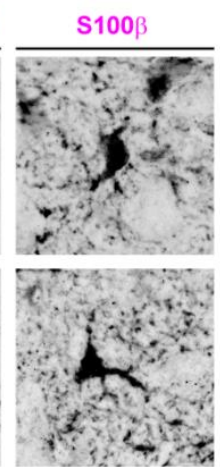

Gja1 mRNA

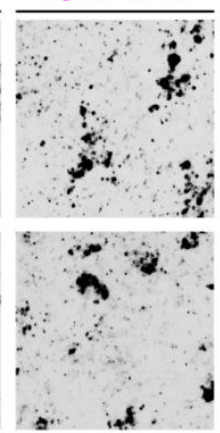

Aldh111-GFP
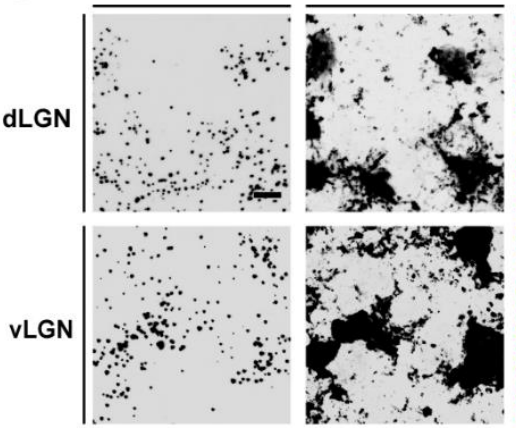

I

Smo mRNA

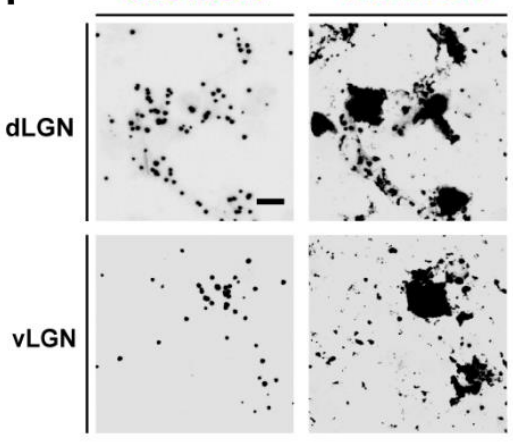

B

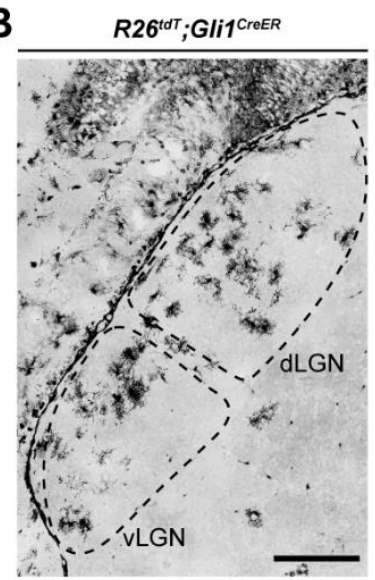

Merge

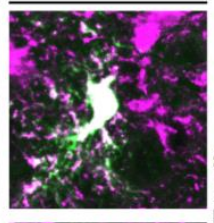

D

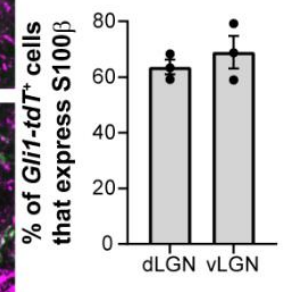

Merge

F
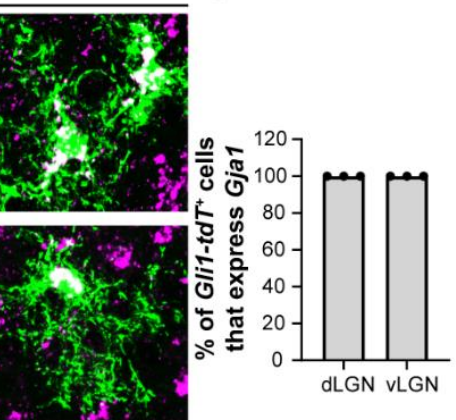

Merge

H
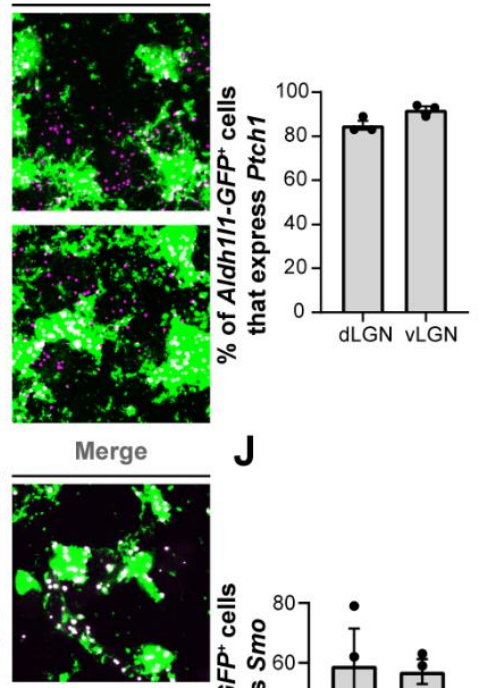

J

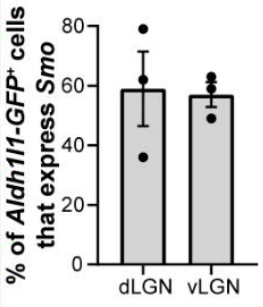




\section{Figure 2. Expression of SHH signaling molecules by astrocytes in visual thalamus}

(A) Raw transcript reads of mRNAs for downstream SHH signaling components in P3 dLGN and vLGN by RNAseq. Each data point represents a different biological replicate and bars depict means \pm SEM.

(B) Presence of Gli1-tdT+ cells in dLGN and vLGN of P7 R26 tdT;Gli1 CreER mice.

(C) IHC for S100ß in P7 R26 tdT; Gli1 CreER mice revealed S100ß expression in Gli1-tdT+ cells in visual thalamus.

(E) Quantification of percentage of Gli1-tdT+ cells that express S100B in P7 visual thalamus. Each data point represents one biological replicate and bars depict means \pm SEM ( $n=3$ mice for each region).

(D) ISH for Gja1 in P7 R26 ${ }^{\text {tdT }}$;Gli1CreER mice revealed expression of Gja1 mRNA by Gli1-tdT+ cells in visual thalamus.

(F) Quantification shows $100 \%$ of Gli1-tdT+ cells express the astrocytic marker Gja1 in P7 visual thalamus. Each data point represents one biological replicate and bars depict means \pm SEM ( $n=3$ mice for each region).

(G) RNAscope-based ISH detected Ptch1 mRNA in dLGN and vLGN of P3 Aldh1/1-GFP mice. This revealed expression of Ptch1 mRNA in the cell bodies as well as in the processes of Aldh1/1-GFP+ astrocytes.

(H) Quantification of percentage of Aldh1/1-GFP+ astrocytes that express Ptch1 mRNA in P3 visual thalamus. Each data point represents one biological replicate and bars depict means \pm SEM ( $n=3$ mice for each region).

(I) RNAscope-based ISH detected Smo mRNA in dLGN and vLGN of P3 Aldh1/1-GFP mice. This revealed expression of Smo mRNA in the cell bodies as well as in the processes of Aldh1/1-GFP+ astrocytes.

(J) Quantification of percentage of Aldh1/1-GFP+ astrocytes that express Smo mRNA in P3 visual thalamus. Each data point represents one biological replicate and bars depict means \pm SEM ( $n=3$ mice for each region).

Scale bars in B: $200 \mu \mathrm{m}$ and in C, E, G, I: $10 \mu \mathrm{m}$. 
A

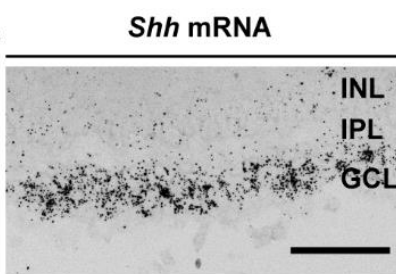

C

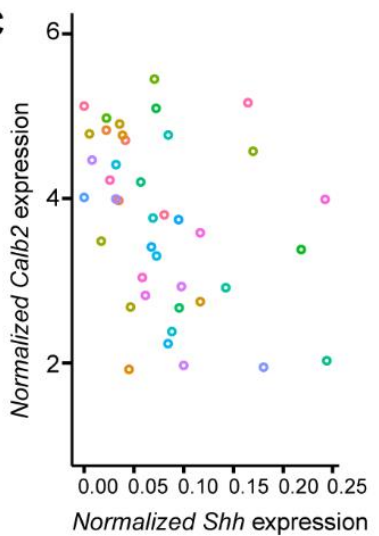

E

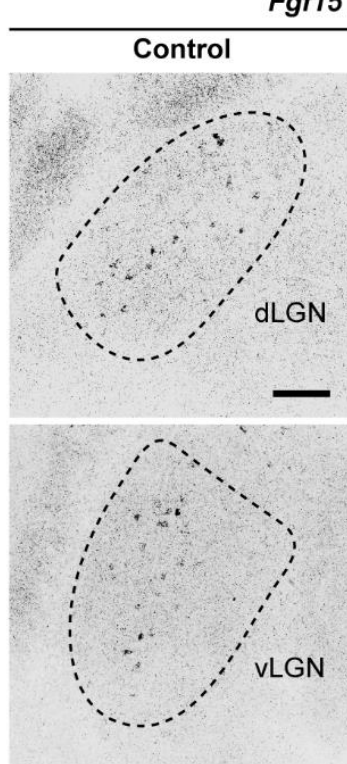

B Shh mRNA

CALB2

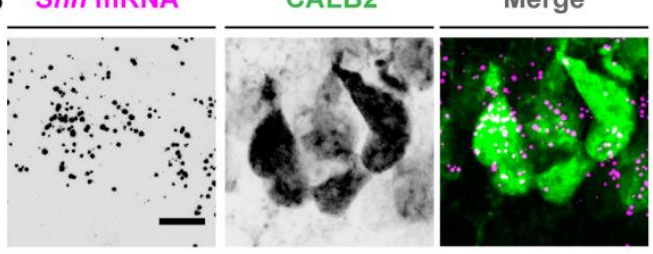

Different RGC types clusters

$0010_{15} 29$ 02016
0030
0017

$040180_{32}$

00519033

80602034

$8070_{21}^{21} 35$

$0090_{23} 37$

10024038

$0_{12026040}$

$\mathrm{O}_{13} \mathrm{O}_{27} \mathrm{O}_{41}$

O 14028 .....

D
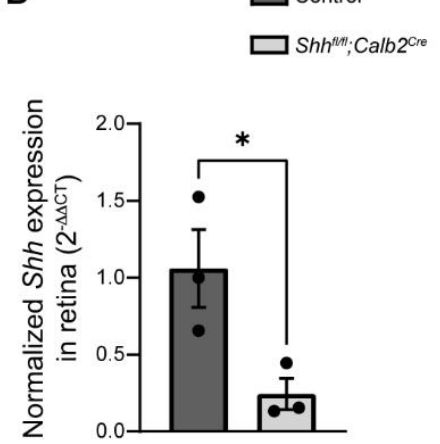

F $\mathrm{Shh}^{f / f f l} ; \mathrm{Calb2}^{\mathrm{Cre}}$
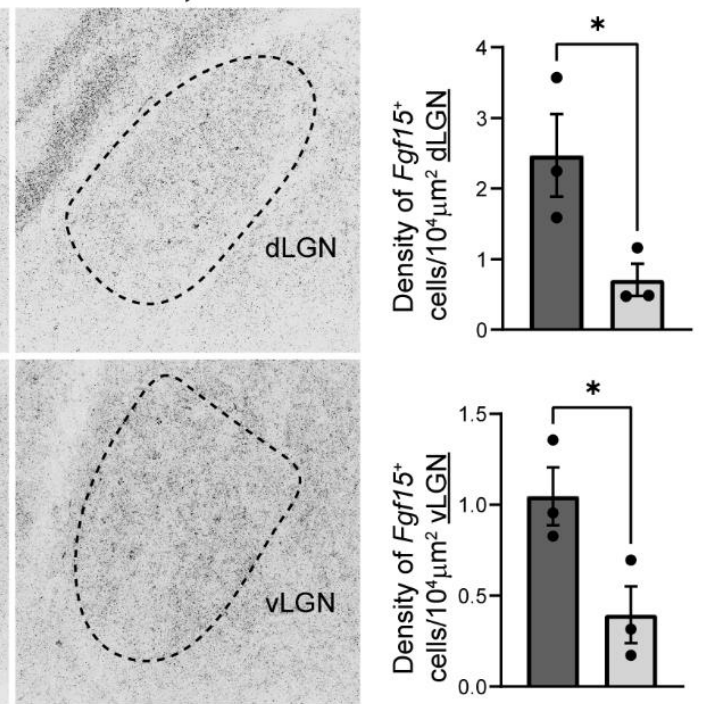


\section{Figure 3. RGC-derived SHH is important for Fgf15 expression in visual thalamus}

(A) RNAscope-based ISH revealed dense Shh mRNA in the GCL of P3 retina (inner nuclear layer, INL; inner plexiform layer, IPL; ganglion cell layer, GCL).

(B) RNAscope-based ISH revealed Shh mRNA in CALB2+ cells in the GCL of P3 retina.

(C) Single-cell RNAseq data (from Rheaume et al., 2018) analyzed to show Calb2 and Shh mRNA expression by different subtypes of RGCs in P5 mouse retina.

(D) qRT-PCR showed a reduction in Shh mRNA in retina of P3 Sh fflft; Calb2 ${ }^{\text {Cre }}$ mice compared to controls. Each data point represents one biological replicate and bars depict means \pm SEM. Asterisks $\left(^{*}\right)$ indicate $P<0.05$ by Student's $t$-test $(n=3$ mice for each group).

(E) ISH revealed reduced Fgf15 expression in dLGN and vLGN of P3 Shh f/fli; Calb2 ${ }^{\text {Cre }}$ mutants compared to controls.

(F) Quantification for density of Fgf15+ cells in dLGN and vLGN of P3 control and Shht/fli;Calb2Cre mutant mice. Each data point represents one biological replicate and bars depict means \pm SEM. Asterisks $\left({ }^{*}\right)$ indicate ${ }^{*} P<0.05$ by Student's $t$-test ( $n=3$ mice for each group).

Scale bars in A, E: $100 \mu \mathrm{m}$ and in $\mathrm{B}: 10 \mu \mathrm{m}$. 
bioRxiv preprint doi: https://doi.org/10.1101/2022.02.22.481508; this version posted February 22, 2022. The copyright holder for this preprint (which was not certified by peer review) is the author/funder. All rights reserved. No reuse allowed without permission.

A

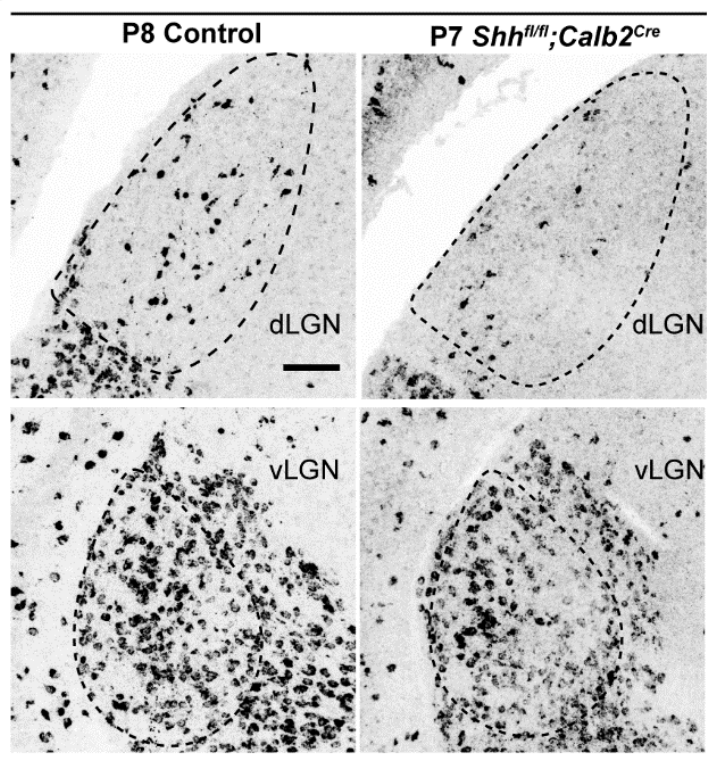

C

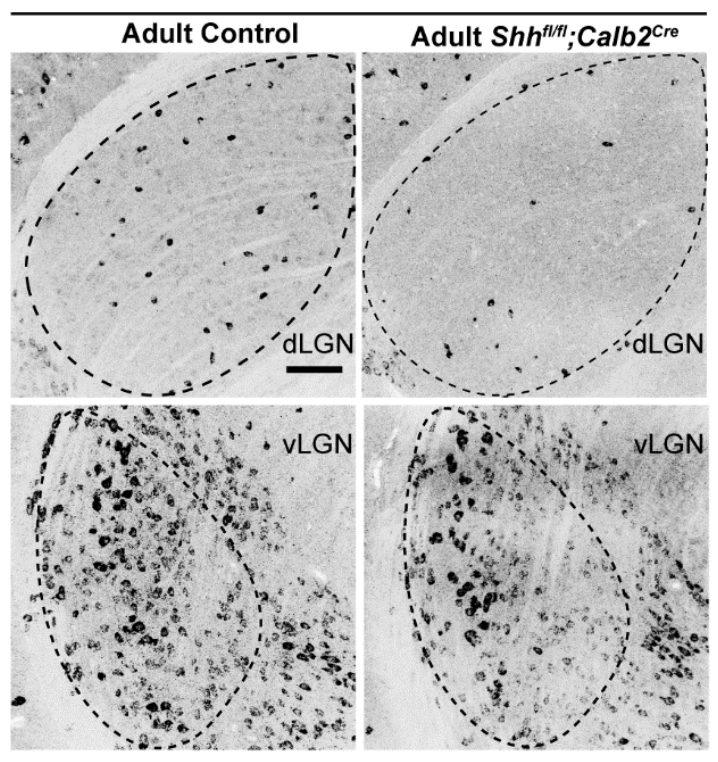

B
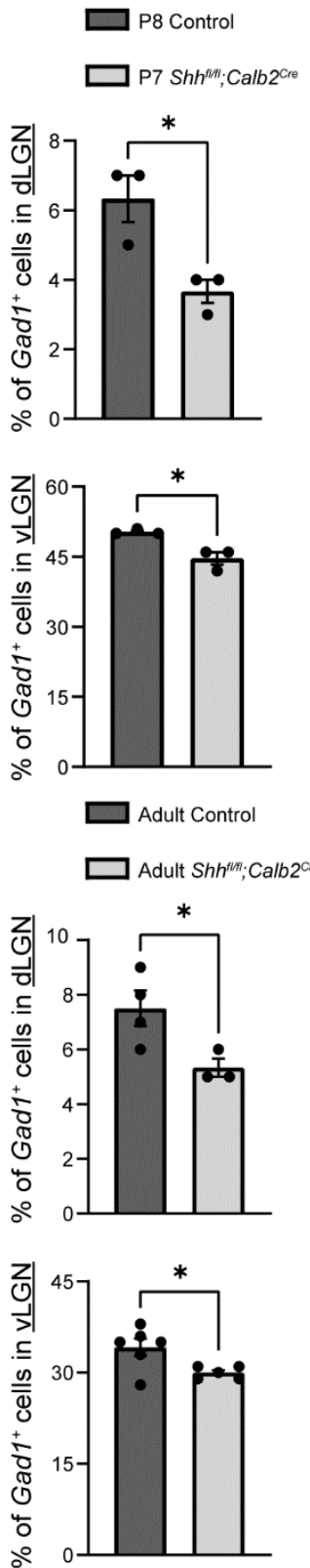


\section{Figure 4. RGC-derived SHH is required for the recruitment of Gad1+ interneurons into visual thalamus}

(A) ISH revealed a reduction in Gad1+ cells in dLGN and vLGN of P7 Shht/fli $;$ Calb2 ${ }^{\text {Cre }}$ mutants compared with controls.

(B) Quantification of percentage of Gad1+ cells in dLGN and vLGN of P7 Shht/fl; Calb2 ${ }^{\text {Cre }}$ and control mice. Each data point represents one biological replicate and bars depict means \pm SEM. Asterisks $\left(^{*}\right)$ indicate ${ }^{*} P<0.05$ by Student's $t$-test $(n=3$ mice for each group).

(C) ISH revealed a reduction in Gad1+ cells in dLGN and vLGN of $>\mathrm{P90} S h h^{f / f t /}$;Calb2 ${ }^{\text {Cre }}$ mutants compared with controls.

(D) Quantification of percentage of Gad1+ cells in dLGN and vLGN of adult Shh ${ }^{\text {fl/fl }}$;Calb2 ${ }^{\text {Cre }}$ and control mice. Each data point represents one biological replicate and bars depict means \pm SEM. Asterisks $\left({ }^{*}\right)$ indicate ${ }^{*} P<0.05$ by Student's $t$-test ( $n=4$ mice for control dLGN group, $n=3$ mice for mutant dLGN group, $n=6$ mice for control vLGN group, and $n=5$ mice for mutant vLGN group).

Scale bars in A, C: $100 \mu \mathrm{m}$. 


\section{STAR METHODS}

\section{RESOURCE AVAILABILITY}

\section{Lead contact}

Further information and requests for resources and reagents should be directed to and will be fulfilled by the Lead Contact, Michael A. Fox (mafox1@vt.edu).

\section{Materials availability}

Riboprobes generated in this study can be obtained upon request to the Lead Contact.

\section{Data and code availability}

- This paper analyzes two existing and publicly available data: 1) Data from Monavarfeshani et al., 2018 can be found at https://elifesciences.org/articles/33498. The DOI is listed in the key resources table, 2) Data from Rheaume et al., 2018 can be found at https://health.uconn.edu/neuroregeneration-lab/rgc-subtypes-gene-browser/. The accession number is listed in the key resources table. Microscopy and behavioral experiment data reported in this publication will be shared by the lead contact upon request.

- This paper does not report original code.

- Any additional information required to reanalyze the data reported in this paper is available from the lead contact upon request.

\section{EXPERIMENTAL MODEL AND SUBJECT DETAILS}

\section{Animals}

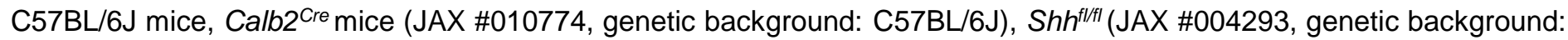
129X1), Nes ${ }^{C r e}$ (JAX \#003771, genetic background: C57BL/6J), and R26tdT (JAX \#007909, genetic background: C57BL/6J) were obtained from The Jackson Laboratory. Math5\%- mice (stock \#042298-UCD, genetic background: C57BL/6J) were obtained from S. W. Wang, University of Texas MD Anderson Cancer Center, Houston, TX. Aldh1/1-GFP mice (stock \#011015-UCD, genetic background: FVB/N) were provided by S. Robel, Virginia Tech, Roanoke, VA. R26 floxstop-TeNT (MGI \#3839913, genetic background: C57BL/6J) mice were obtained from A. Maximov, The Scripps Research Institute, La Jolla, CA, after receiving approval from M. Goulding, The Salk Institute for Biological Studies, La Jolla, CA. We were never able

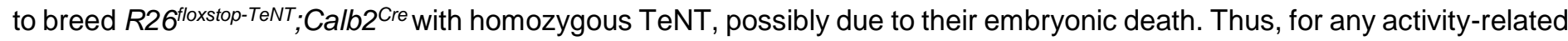
experiment presented in Figures 1 and S1, mice heterozygous for the TeNT allele were considered as mutant mice. The key resources table includes sequences for the genotyping primers. Gli1 CreER mice (Ahn and Joyner, 2005) were crossed with Ai14 reporter mice (JAX \#007914) to generate $R 26^{t d T}$; Gli1CreER mice. Both sexes were used for all experiments. Animals had ad libitum access to water and food and were housed in a temperature-controlled environment and in a 12-hour light/dark cycle. The experiments were approved by Virginia Tech Institutional Animal Care and Use Committee.

\section{METHOD DETAILS}

\section{Preparation of tissue and IHC}

As previously described, tribromoethanol (Avertin) was intraperitoneally injected into mice at a concentration of $12.5 \mu \mathrm{g} / \mathrm{ml}$. The animals were transcardially perfused with PBS and 4\% paraformaldehyde (PFA, pH 7.4) (Su et al., 2010). Brains were kept overnight at $4{ }^{\circ} \mathrm{C}$ in $4 \%$ PFA, and then transferred to $30 \%$ sucrose in PBS for at least 48 hours. The fixed brains were embedded in Tissue Freezing Medium (Electron Microscopy Sciences) and $16 \mu \mathrm{m}$ thick sections were cryosectioned on a Leica CM1850 cryostat. Following air-drying for 30 minutes, slides were incubated in IHC blocking buffer $(2.5 \%$ bovine serum albumin, $5 \%$ normal goat serum, $0.1 \%$ Triton-X in PBS) for 30 minutes. Primary antibodies were diluted in blocking buffer and incubated on the sections at $4^{\circ} \mathrm{C}$ for $>18$ hours (information on the antibodies is available in the key resources table). Following washing with PBS, fluorophore-conjugated secondary antibodies (Invitrogen) were incubated on tissue sections for 1 hour at room temperature. The sections were stained with 4',6-diamidino-2-phenylindole (DAPI) after several washes in PBS and mounted with Vectashield (Vector Laboratories).

\section{Riboprobe production}


Riboprobes were generated as described previously (Monavarfeshani et al., 2018; Su et al., 2010). Plasmids carrying Fgf15 (Cat\#MMM1013-202768318) were purchased from GE Dharmacon. Gad1 1 Kb cDNA (corresponding to nucleotides 10992081) and Gja1 1.1 Kb cDNA (corresponding to nucleotides 714-1854) were generated using SuperScript II Reverse Transcriptase First Strand cDNA Synthesis kit (Invitrogen, Cat\#18064014) and the manufacturer's protocol. The information for the sequence of cloning primers is in the key resources table. cDNA was then cloned into the pGEM-T Easy vector (Promega, Cat\#A1360). We generated sense and antisense riboprobes against Fgf15, Gad1, and Gja1 from linearized plasmids using DIG- or FL-labeled uridylyltransferase (Roche, Cat\#11685619910 and Cat\#11277073910) and MAXIscript in vitro Transcription Kit (Ambion, Cat\#AM1312). Riboprobes were hydrolyzed into 500 bp fragments by adding $6 \mu$ l of $\mathrm{Na}_{2} \mathrm{CO}_{3}(1 \mathrm{M}), 4 \mu \mathrm{l}$ of $\mathrm{NaHCO}_{3}(1 \mathrm{M})$, and $80 \mu \mathrm{l}$ of water at $60^{\circ} \mathrm{C}$. Following precipitation with ethanol, the riboprobes were dissolved in RNAase-free water.

\section{Tamoxifen administration}

Tamoxifen was dissolved in corn oil at $5 \mathrm{mg} / \mathrm{ml}$. Tamoxifen was administered by intragastric injection to $R 26^{\text {tdT }}$;Gli1CreER pups at P0.

\section{In situ hybridization (ISH) with in-house generated riboprobes}

We performed ISH using the generated riboprobes on PFA-fixed, cryosectioned $16 \mu \mathrm{m}$ tissue as described previously (Monavarfeshani et al., 2018). The sections were fixed in 4\% PFA for 10 minutes, washed with PBS, and incubated with proteinase $\mathrm{K}(1 \mu \mathrm{g} / \mathrm{mL}$ in $50 \mathrm{mM}$ Tris $\mathrm{pH} 7.5,5 \mathrm{mM}$ EDTA) solution for 10 minutes. After being washed with PBS, sections were incubated for 5 minutes in 4\% PFA, washed with PBS, and then incubated for 10 minutes in acetylation solution $(0.25 \%$ acetic anhydride, $20 \mathrm{mM}$ hydrochloric acid and $1.33 \%$ triethanolamine). In order to permeabilize them, sections were incubated for 30 minutes in $1 \%$ triton in PBS. For blocking endogenous peroxidase, sections were incubated in $0.3 \%$ hydrogen peroxide in PBS for 30 minutes, then rinsed in PBS. We equilibrated the sections in hybridization solution (50 mL of prehyb solution, $1.6 \mathrm{ml}$ of $5 \mathrm{mg} / \mathrm{ml}$, and $25 \mathrm{mg}$ Roche yeast RNA) for 1 hour, and then incubated them in heat-denatured diluted riboprobes $\left(10\right.$ minutes at $\left.80^{\circ} \mathrm{C}\right)$ overnight at $65^{\circ} \mathrm{C}$. On the next day, slides were rinsed with $0.2 \mathrm{x}$ saline-sodium citrate solution followed by tris-buffered saline (TBS). Following 1 hour incubation in blocking buffer (10\% lamb serum, $0.2 \%$ Roche blocking reagent in TBS), the slides were incubated overnight at $4 \circ \mathrm{C}$ in HRP-conjugated anti-DIG or anti-FL antibodies. On day three, riboprobes were identified using a Tyramide Signal Amplification (TSA) system (PerkinElmer, Cat\#NEL753001KT).

\section{ISH with commercially generated RNAscope riboprobes}

The probes used were RNA scope probe-Mm-Smo (Advanced Cell Diagnostics, ACD, Cat\#318411), RNA scope probeMm-Ptch1-C2 (ACD, Cat\#402811-C2), RNA scope probe-Mm-Shh-C3 (ACD, Cat\#314361-C3), RNA scope 3-plex positive control probe-mm (ACD, Cat\#320881), and RNA scope 3-plex negative control probe-mm (ACD, Cat\#320871). PFA-fixed, cryosectioned $16 \mu \mathrm{m}$ tissue were processed for RNA Scope Multiplex (Cat\#323100) using manufacturer's protocol (https://acdbio.com). Briefly, sections were dehydrated by ethanol treatment and then pretreated with target retrieval reagent and protease III. Following the hybridization of probes, we amplified signals on sections using the TSA system.

\section{Intraocular injection of CTB}

We anesthetized mice with isoflurane or hypothermia for intraocular injections, as described previously (Jaubert-Miazza et al., 2005). A fine glass pipette attached to a picospritzer was used to inject 1-2 $\mu$ of CTB (Thermo Fisher Scientific, CAT\#C22841, CAT\#C34776), $1 \mathrm{mg} / \mathrm{ml}$, intravitreally into the eye. After 2-3 days, mice were perfused, and their PFA-fixed brains were sectioned $(100 \mu \mathrm{m})$ using a Vibratome (HM650v, Thermo Fisher Scientific) and mounted with Vectashield.

\section{Imaging}

A Zeiss LSM700 confocal microscope was used for image acquisition. Each representative image in the figure is a maximum intensity projection. Colocalization was confirmed using single-plane images.

\section{qRT-PCR}

RNA was isolated from non-pooled P3 control and Shfflit; Calb2 ${ }^{\text {Cre }}$ mutant retina using the Bio-Rad Total RNA Extraction from Fibrous and Fatty Tissue kit (Bio-Rad, Cat\#7326870) and manufacturer's protocol. Using this RNA, cDNAs were 
generared with SuperScript ${ }^{\mathrm{TM}}$ II Reverse Transcriptase (Thermo Fisher Scientific, Cat\#18064022). qPCR was performed using iTaq ${ }^{\mathrm{TM}}$ Universal SYBR ${ }^{\circledR}$ Green Supermix (Bio-Rad, Cat\#1725124) on a CFX Connect Real-Time system (BioRad). Cyling conditions for 500 or $1000 \mathrm{ng}$ of cDNA are as follows: $95^{\circ} \mathrm{C}$ for 30 seconds and 42 cycles of amplification $\left(95^{\circ} \mathrm{C}\right.$ for 10 seconds, $60^{\circ} \mathrm{C}$ for 30 seconds) followed by a melting curve analysis. Each individual run included separate $18 \mathrm{~S}$ rRNA or glyceraldehyde-3-phosphate dehydrogenase (gapdh) control reactions. Using the $2^{-\Delta \Delta C T}$ method, we determined the relative quantities of RNA (Schmittgen and Livak, 2008). The primer list can be found in the key resources table.

\section{Looming visual stimulus assay}

The looming visual stimulus assay was performed as described previously (Su et al., 2021). Mice were presented with an overhead looming stimuli in a white rectangular arena $(47 \times 37 \times 30 \mathrm{~cm})$. To maintain uniform environmental conditions, the arena was illuminated evenly from above and enclosed in a light-proof, sound-isolating room. One of the corners had an opaque shelter, whose entrance faced the center of the arena. On the stand next to the arena, a camera was mounted to capture mouse behavior. The mice were only tested once each to prevent habituation to the stimulus. Ten minutes prior to the recording of the test, the animals were free to explore the arena and the shelter. Looming stimulus began when the animal moved around the center of the arena. Ten seconds of video was recorded prior to, during, and after the stimulus onset. We manually scored the animal's behavior during 10 seconds of looming stimulus. The reaction time was defined as a period one or more seconds in which the animal either freezes, runs, or hides in the shelter after the stimulus began.

\section{QUANTIFICATION AND STATISTICAL ANALYSIS}

A minimum of three biological replicates per genotype and age were used for all quantification. We did not exclude any data or animals from our analyses. No sex-specific differences were observed. Statistical analyses (Student's $t$-test) were performed using GraphPad Prism (version 8.0.; RRID: SCR_002798). $P<0.05$ values were considered to be significantly different. The figure legends provide $P$ values for all experiments. Data are plotted as mean \pm SEM.

\section{Percentage of Gad1+, Gja1+ and Gli1-tdT' cells}

Images were obtained using 10x magnification. We quantified Gad1+, Gja1+ (by ISH) and Gli1-tdT+ (by R26 ${ }^{\text {tdT }}$;Gli1CreER reporter mice) cells and divided by DAPI+ cells counted in that tissue section. "Count Tool" function in Adobe Photoshop (Adobe Inc., version: 21.1.2) was utilized for counting purposes.

\section{Density of Fgf15+ cells}

Images were obtained using 10x magnification. We quantified $\mathrm{Fgfl}^{+}$(by ISH) cells and normalized them to the area of dLGN or vLGN. Areas were measured by outlining the boundaries of dLGN or vLGN using ZEN 2.3 SP1 FP1 (black) edition (version: 14.0.12.201, Carl Zeiss).

\section{CTB analysis}

Images were obtained using 10x magnification and Fiji ImageJ (version: 1.52p, NIH) was used for analyses. Using "Split Channels", CTB 488 and CTB 555 signal were separated. For each channel, contrast was enhanced ("Enhance Contrast", $0.3 \%$ ), background was subtracted ("Subtract Background", 1000 pixels and "Math", "Subtract"), and channels were binarized ("Make Binary"). The dLGN boundary was drawn manually by utilizing the "Freehand selections" tool. Using this boundary and "Area fraction" on each binarized channel, percentage of dLGN covered by ipsiRGCs or contraRGCs was determined. To obtain the overlap channel, we used "AND" function in "Image Calculator". On this channel, the dLGN boundary was drawn and "Area fraction" gave the percentage of dLGN area covered by the overlap of ipsi and contraRGCs projections.

\section{RNAscope analysis}

Images were acquired at 20x magnification. We used ACD's scoring criteria for this analysis (https://acdbio.com/dataanalysisguide). A cell was classified as positive for Ptch1 or Smo (by RNAscope) if it contained at least 10 dots. This was divided by Aldh1/1-GFP+ cells (by Aldh1/1-GFP transgenic line) to obtain percentage of astrocytes that express Ptch1 or Smo in dLGN and vLGN. "Count Tool" function in Adobe Photoshop was utilized for counting purposes.

\section{Calb2 and Shh expression in RGC clusters}


bioRxiv preprint doi: https://doi.org/10.1101/2022.02.22.481508; this version posted February 22, 2022. The copyright holder for this preprint (which was not certified by peer review) is the author/funder. All rights reserved. No reuse allowed without permission.

Single cell data from Rheaume et al., 2018 was downloaded from NCBI GEO (accession \#: GSE115404). Shh (Ensembl ID = ENSMUSG00000002633) and Calb2 (Ensemble ID = ENSMUSG00000003657) expression values were used to generate "ggplot2" on RStudio (version: 1.2.5042, RStudio, Inc.). 


\section{KEY RESOURCES TABLE}

\begin{tabular}{|c|c|c|}
\hline REAGENT or RESOURCE & SOURCE & IDENTIFIER \\
\hline \multicolumn{3}{|l|}{ Antibodies } \\
\hline GFP Polyclonal Antibody (1:250 dilution) & $\begin{array}{l}\text { Thermo Fisher } \\
\text { Scientific }\end{array}$ & $\begin{array}{l}\text { Cat\#A-11122; } \\
\text { RRID:AB_221569 }\end{array}$ \\
\hline Polyclonal Rabbit Anti S100 (1:200 dilution) & Dako & $\begin{array}{l}\text { Cat\# Z0311; } \\
\text { RRID:AB_1001338 } \\
3\end{array}$ \\
\hline Anti-Calretinin Antibody (1:1000 dilution) & Swant & $\begin{array}{l}\text { Cat\#7697; RRID: } \\
\text { AB_2619710 }\end{array}$ \\
\hline Rockland RFP Polyclonal Antibody (1:500 dilution) & $\begin{array}{l}\text { Thermo Fisher } \\
\text { Scientific }\end{array}$ & $\begin{array}{l}\text { Cat\#600-401-379- } \\
\text { RTU; } \\
\text { RRID:AB_2209751 }\end{array}$ \\
\hline Anti-Digoxigenin-POD (1:1000 dilution) & Millipore Sigma & $\begin{array}{l}\text { Cat\#11207733910; } \\
\text { RRID:AB_514500 }\end{array}$ \\
\hline Anti-Fluorescein-POD (1:1000 dilution) & Millipore Sigma & $\begin{array}{l}\text { Cat\#11426346910; } \\
\text { RRID:AB_840257 }\end{array}$ \\
\hline \multicolumn{3}{|l|}{ Biological samples } \\
\hline$R 26^{t d T} ;$ Gli $1^{\text {CreER }}$ brains & $\begin{array}{l}\text { A.D.R Garcia, Drexel } \\
\text { University }\end{array}$ & $\begin{array}{l}\text { JAX \#007913, } \\
\text { \#007914; RRID: } \\
\text { IMSR_JAX:007913, } \\
\text { IMSR_JAX:007914 }\end{array}$ \\
\hline \multicolumn{3}{|l|}{ Chemicals, peptides, and recombinant proteins } \\
\hline Fluorescein RNA Labeling Mix & Roche & Cat\#11685619910 \\
\hline DIG RNA Labeling Mix & Roche & Cat\#11277073910 \\
\hline SuperScript ${ }^{\mathrm{TM}}$ II Reverse Transcriptase & $\begin{array}{l}\text { Thermo Fisher } \\
\text { Scientific }\end{array}$ & Cat\#18064022 \\
\hline $\begin{array}{l}\text { Cholera Toxin Subunit B ( CTB, Recombinant), Alexa } \\
\text { Fluor }^{\mathrm{TM}} 488 \text { Conjugate }\end{array}$ & $\begin{array}{l}\text { Thermo Fisher } \\
\text { Scientific }\end{array}$ & CAT\#C22841 \\
\hline Tamoxifen & Sigma & CAT\#T5648-1G \\
\hline CTB (Recombinant), Alexa Fluor ${ }^{\mathrm{TM}} 555$ Conjugate & $\begin{array}{l}\text { Thermo Fisher } \\
\text { Scientific }\end{array}$ & CAT\#C34776 \\
\hline \multicolumn{3}{|l|}{$\begin{array}{l}\text { All other chemicals were purchased from Sigma, } \\
\text { Tocris Bioscience, or Fisher }\end{array}$} \\
\hline \multicolumn{3}{|l|}{ Critical commercial assays } \\
\hline $\begin{array}{l}\text { SuperScript II Reverse Transcriptase First Strand } \\
\text { cDNA Synthesis kit }\end{array}$ & Invitrogen & Cat\#18064014 \\
\hline pGEM-T Easy Vector Systems & Promega & Cat\#A1360 \\
\hline MAXIscript in vitro Transcription Kit & Ambion & Cat\#AM1312 \\
\hline Tyramide Signal Amplification system & PerkinElmer & Cat\#NEL753001KT \\
\hline iTaq $^{\text {TM }}$ Universal SYBR ${ }^{\circledR}$ Green Supermix & Bio-Rad & Cat\#1725124 \\
\hline $\begin{array}{l}\text { Bio-Rad Total RNA Extraction from Fibrous and Fatty } \\
\text { Tissue kit }\end{array}$ & Bio-Rad & Cat\#7326870 \\
\hline RNAscope® Multiplex Fluorescent Reagent Kit V2 & $\begin{array}{l}\text { Advanced Cell } \\
\text { Diagnostics (ACD) }\end{array}$ & Cat\#323100 \\
\hline \multicolumn{3}{|l|}{ Deposited data } \\
\hline $\begin{array}{l}\text { RNAseq datasets for the developing mouse dLGN } \\
\text { and vLGN }\end{array}$ & $\begin{array}{l}\text { Monavarfeshani et } \\
\text { al., } 2018\end{array}$ & $\begin{array}{l}\text { DOI: } \\
\text { https://doi.org/10.75 } \\
\text { 54/eLife.33498.006 }\end{array}$ \\
\hline single-cell RNAseq dataset for RGC subtypes & Rheaume et al., 2018 & $\begin{array}{l}\text { Accession \# } \\
\text { accession number } \\
\text { GSE115404 }\end{array}$ \\
\hline
\end{tabular}




\begin{tabular}{|c|c|c|}
\hline C57BL/6J mice & $\begin{array}{l}\text { The Jackson } \\
\text { Laboratory }\end{array}$ & $\begin{array}{l}\text { JAX\#000664; } \\
\text { RRID:IMSR_JAX:0 } \\
00664\end{array}$ \\
\hline Calb2 & $\begin{array}{l}\text { The Jackson } \\
\text { Laboratory }\end{array}$ & $\begin{array}{l}\text { JAX\#010774; } \\
\text { RRID:IMSR_JAX:0 } \\
\text { 10774 }\end{array}$ \\
\hline$S h h^{f / f t}$ & $\begin{array}{l}\text { The Jackson } \\
\text { Laboratory }\end{array}$ & $\begin{array}{l}\text { JAX\#004293; } \\
\text { RRID:IMSR_JAX:0 } \\
04293\end{array}$ \\
\hline $\mathrm{Nes}^{\mathrm{Cre}}$ & $\begin{array}{l}\text { The Jackson } \\
\text { Laboratory }\end{array}$ & $\begin{array}{l}\text { JAX\#003771; } \\
\text { RRID:IMSR_JAX:0 } \\
03771\end{array}$ \\
\hline Aldh1/1-GFP & $\begin{array}{l}\text { S. Robel, Virginia } \\
\text { Tech }\end{array}$ & $\begin{array}{l}\text { Stock\#011015- } \\
\text { UCD; RRID: } \\
\text { MMRRC_011015- } \\
\text { UCD }\end{array}$ \\
\hline$R 26^{\text {toxstop-TeNT }}$ & $\begin{array}{l}\text { A. Maximov, The } \\
\text { Scripps Research } \\
\text { Institute }\end{array}$ & $\begin{array}{l}\text { MGl:3839913; } \\
\text { Zhang et al., } 2008\end{array}$ \\
\hline$R 26^{t d T}(\mathrm{Ai} 14)$ & $\begin{array}{l}\text { The Jackson } \\
\text { Laboratory }\end{array}$ & $\begin{array}{l}\text { JAX\#007914; } \\
\text { RRID: } \\
\text { IMSR_JAX:007914 }\end{array}$ \\
\hline Glit $^{\text {CreER }}$ & $\begin{array}{l}\text { Ahn and Joyner, } \\
2005\end{array}$ & $\begin{array}{l}\text { JAX\#007913; } \\
\text { RRID: } \\
\text { IMSR_JAX:007913 }\end{array}$ \\
\hline$R 26^{t d T}$ & $\begin{array}{l}\text { The Jackson } \\
\text { Laboratory }\end{array}$ & $\begin{array}{l}\text { JAX\#007909; } \\
\text { RRID:IMSR_JAX:0 } \\
07909\end{array}$ \\
\hline Math5 $5^{-}$ & $\begin{array}{l}\text { S. W. Wang, } \\
\text { University of Texas } \\
\text { MD Anderson Cancer } \\
\text { Center }\end{array}$ & $\begin{array}{l}\text { Stock\# 042298- } \\
\text { UCD; } \\
\text { RRID:MMRRC_042 } \\
\text { 298-UCD }\end{array}$ \\
\hline \multicolumn{3}{|l|}{ Oligonucleotides } \\
\hline $\begin{array}{l}\text { Gad1 cloning primer } \\
\text { F:TGTGCCCAACTGGTCCT; } \\
\text { R:TGGCCGATGATTCTGGTT }\end{array}$ & $\begin{array}{l}\text { Integrated DNA } \\
\text { Technologies }\end{array}$ & $\mathrm{N} / \mathrm{A}$ \\
\hline $\begin{array}{l}\text { Gja1 cloning primer } \\
\text { F:CGTGAAGGGAAGAAGCGA } \\
\text { R:GCCTGCAAACTGCCAAGT }\end{array}$ & $\begin{array}{l}\text { Integrated DNA } \\
\text { Technologies }\end{array}$ & $\mathrm{N} / \mathrm{A}$ \\
\hline $\begin{array}{l}\text { Shh qPCR primer } \\
\text { F:ACGTAGCCGAGAAGACCCTA } \\
\text { R:ACTTGTCTTTGCACCTCTGAGT }\end{array}$ & $\begin{array}{l}\text { Integrated DNA } \\
\text { Technologies }\end{array}$ & $N / A$ \\
\hline $\begin{array}{l}\text { Gapdh qPCR primer } \\
\text { F:CGTCCCGTAGACAAAATGGT; } \\
\text { R:TTGATGGCAACAATCTCCAC }\end{array}$ & $\begin{array}{l}\text { Integrated DNA } \\
\text { Technologies }\end{array}$ & $\mathrm{N} / \mathrm{A}$ \\
\hline $\begin{array}{l}\text { 18s qPCR primer } \\
\text { F:GGACCAGAGCGAAAGCATTTG; } \\
\text { R:GCCAGTCGGCATCGTTTATG }\end{array}$ & $\begin{array}{l}\text { Integrated DNA } \\
\text { Technologies }\end{array}$ & $\mathrm{N} / \mathrm{A}$ \\
\hline $\begin{array}{l}\text { Cre genotyping primer } \\
\text { F:CGTACTGACGGTGGGAGAAT } \\
\text { R:TGCATGATCTCCGGTATTGA }\end{array}$ & $\begin{array}{l}\text { Integrated DNA } \\
\text { Technologies }\end{array}$ & $\mathrm{N} / \mathrm{A}$ \\
\hline $\begin{array}{l}\text { tdT genotyping primer } \\
\text { F: ACCTGGTGGAGTTCAAGACCATCT } \\
\text { R:TTGATGACGGCCATGTTGTTGTCC }\end{array}$ & $\begin{array}{l}\text { Integrated DNA } \\
\text { Technologies }\end{array}$ & $\mathrm{N} / \mathrm{A}$ \\
\hline
\end{tabular}




\begin{tabular}{|c|c|c|}
\hline $\begin{array}{l}\text { GFP genotyping primer } \\
\text { F:AAGTTCATCTGCACCACCG } \\
\text { R:TCCTTGAAGAAGATGGTGCG }\end{array}$ & $\begin{array}{l}\text { Integrated DNA } \\
\text { Technologies }\end{array}$ & $\mathrm{N} / \mathrm{A}$ \\
\hline $\begin{array}{l}\text { TeNT genotyping primer } \\
\text { FA:AAAGTCGCTCTGAGTTGTTAT } \\
\text { RA:GGAGCGGGAGAAATGGATATG } \\
\text { SA:CATCAAGGAAACCCTGGACTACTG }\end{array}$ & $\begin{array}{l}\text { Integrated DNA } \\
\text { Technologies }\end{array}$ & $\mathrm{N} / \mathrm{A}$ \\
\hline $\begin{array}{l}\text { Math5 } 5^{-/} \text {genotyping primer (to see the wild type band) } \\
\text { F:ATGGCGCTCAGCTACATCAT } \\
\text { R:GGGTCTACCTGGAGCCTAGC }\end{array}$ & $\begin{array}{l}\text { Integrated DNA } \\
\text { Technologies }\end{array}$ & $\mathrm{N} / \mathrm{A}$ \\
\hline \multicolumn{3}{|l|}{ See Table S1 for other primers } \\
\hline \multicolumn{3}{|l|}{ Recombinant DNA } \\
\hline Mouse Fgf15 cDNA & Horizon (Dharmacon) & $\begin{array}{l}\text { Cat\#MMM1013- } \\
\text { 202768318, Clone } \\
\text { ID: } 5066286\end{array}$ \\
\hline RNA scope probe-Mm-Smo & ACD & Cat\#318411 \\
\hline RNA scope probe-Mm-Ptch1-C2 & ACD & Cat\#402811-C2 \\
\hline RNA scope probe-Mm-Shh-C3 & ACD & Cat\#314361-C3 \\
\hline RNA scope 3-plex positive control probe-mm & ACD & Cat\#320881 \\
\hline RNA scope 3-plex negative control probe-mm & ACD & Cat\#320871 \\
\hline \multicolumn{3}{|l|}{ Software and algorithms } \\
\hline Prism & GraphPad & $\begin{array}{l}\text { version 8.0.; RRID: } \\
\text { SCR_002798 }\end{array}$ \\
\hline Adobe Photoshop & Adobe Inc. & version: 21.1 .2 \\
\hline ZEN black edition & Carl Zeiss & $\begin{array}{l}\text { version: } \\
\text { 14.0.12.201 }\end{array}$ \\
\hline Fiji ImageJ & $\mathrm{NIH}$ & version: $1.52 p$ \\
\hline RStudio & RStudio, Inc. & version: 1.2 .5042 \\
\hline \multicolumn{3}{|l|}{ Other } \\
\hline Fgf15 riboprobe & This manuscript & $\mathrm{N} / \mathrm{A}$ \\
\hline Gad1 riboprobe & This manuscript & $\mathrm{N} / \mathrm{A}$ \\
\hline Gja1 riboprobe & This manuscript & $\mathrm{N} / \mathrm{A}$ \\
\hline
\end{tabular}


bioRxiv preprint doi: https://doi.org/10.1101/2022.02.22.481508; this version posted February 22, 2022. The copyright holder for this preprint (which was not certified by peer review) is the author/funder. All rights reserved. No reuse allowed without permission.

\section{TABLE S1}

\begin{tabular}{|l|l|l|}
\hline Oligonucleotides & \\
\hline Neo genotyping primer (to see the mutant Math5 band) & Integrated DNA & N/A \\
F:GCCGGCCACAGTCGATGAATC & Technologies & \\
R:CATTGAACAAGATGGATTGCA & & \\
\hline Shh ${ }^{f / f t}$ genotyping primer & Integrated DNA & N/A \\
F:CAGAGAGCATTGTGGAATGG & Technologies & \\
R:CAGACCCTTCTGCTCATGG & & \\
\hline
\end{tabular}


bioRxiv preprint doi: https://doi.org/10.1101/2022.02.22.481508; this version posted February 22, 2022. The copyright holder for this preprint (which was not certified by peer review) is the author/funder. All rights reserved. No reuse allowed without permission.
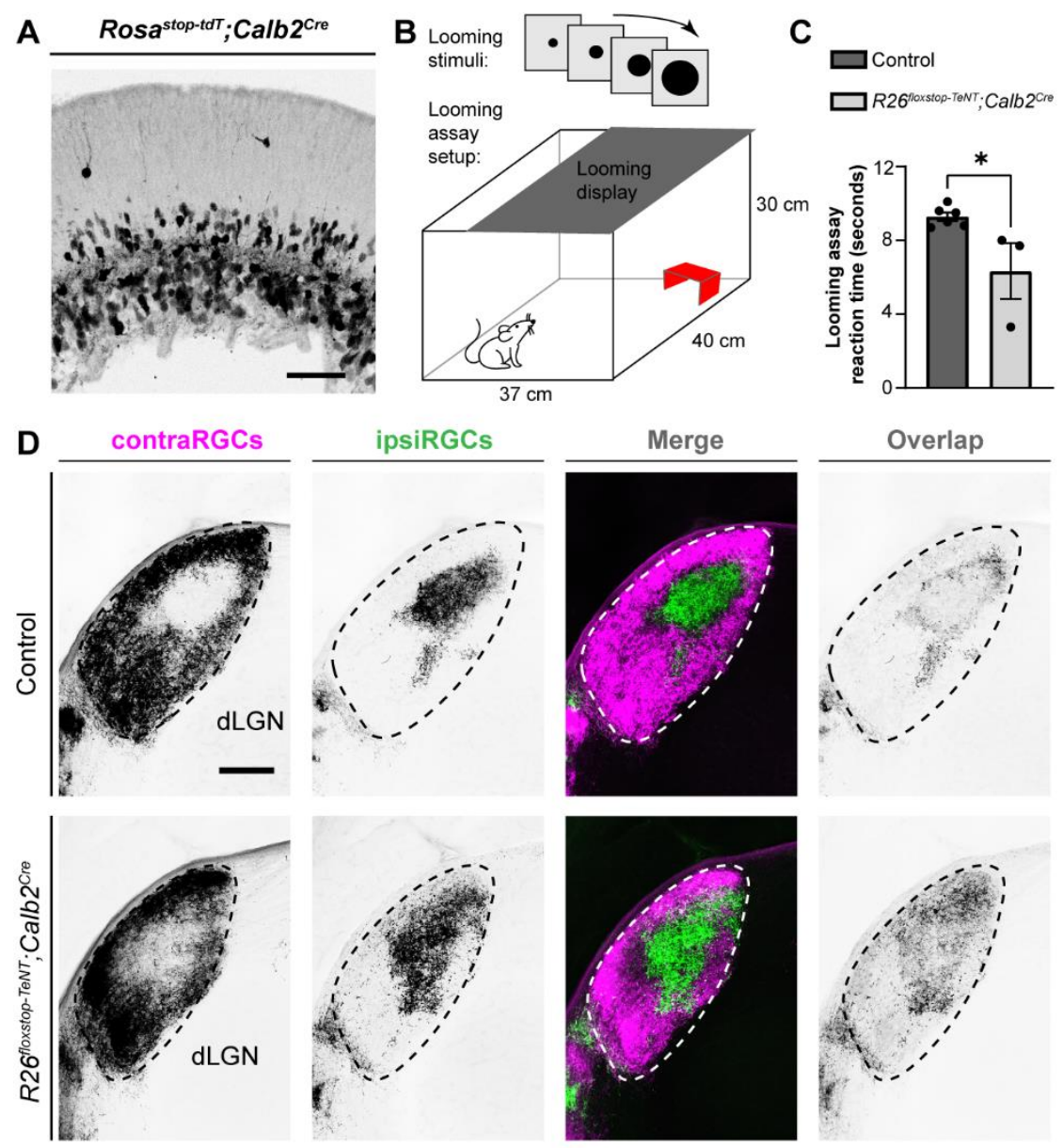

$\mathbf{E}$
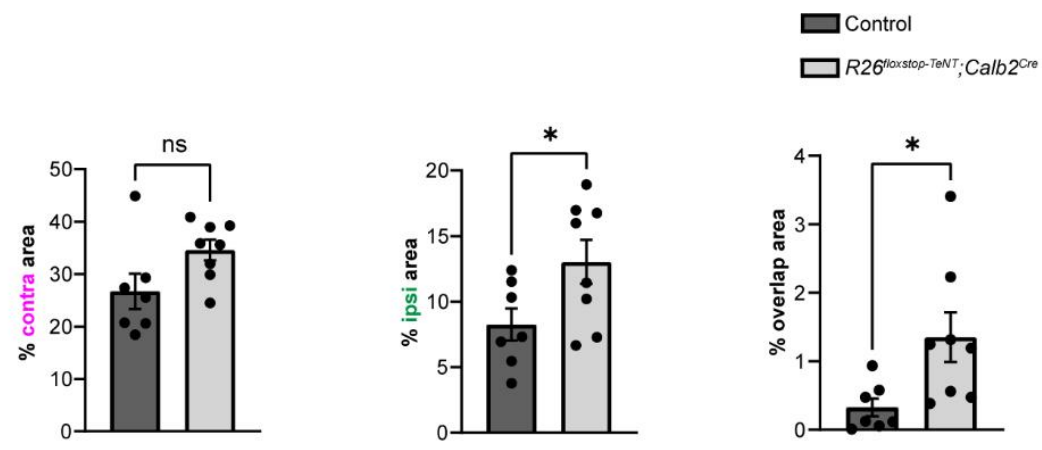
Figure S1. Anatomical and functional characterization of $R_{2} 6^{\text {floxstop-TeNT} ; C a l b 2}{ }^{\text {Cre }}$ mice

(A) Expression of tdT in the GCL of PO Rosastop-tdT;Calb2 Cre mouse retina.

(B) Schematic representation of the behavioral response to a looming visual stimulus.

(C) Adult R26 floxstop-TeNT;Calb2 Cre mutants had reduced reaction times to a looming visual stimulus compared with controls. Each data point represents one biological replicate and bars depict means \pm SEM. Asterisks $\left({ }^{*}\right)$ indicate ${ }^{*} P<0.05$ by Student's $t$-test ( $n=6$ mice for control group and $n=3$ mice for mutant group).

(D) CTB-labeled eye-specific retinal projections to dLGN in P16 control and P24 R26 floxstop-TeNT;Calb2Cre mutant mice.

(E) Quantification of the percentage of dLGN area covered by contraRGCs projections, ipsiRGCs projections, or overlapping eye-specific projections in controls and $R 26^{\text {floxstop-TeNT; }}$ Calb2 $2^{\text {Cre }}$ mutants. Each data point represents one biological replicate and bars depict means \pm SEM. Asterisks $\left({ }^{*}\right)$ indicate ${ }^{*} P<0.05$ by Student's $t$-test $(n=7$ mice for control group and $n=8$ mice for mutant group).

Scale bars in A: $50 \mu \mathrm{m}$ and D: $200 \mu \mathrm{m}$. 
bioRxiv preprint doi: https://doi.org/10.1101/2022.02.22.481508; this version posted February 22, 2022. The copyright holder for this preprint (which was not certified by peer review) is the author/funder. All rights reserved. No reuse allowed without permission.

\section{A}
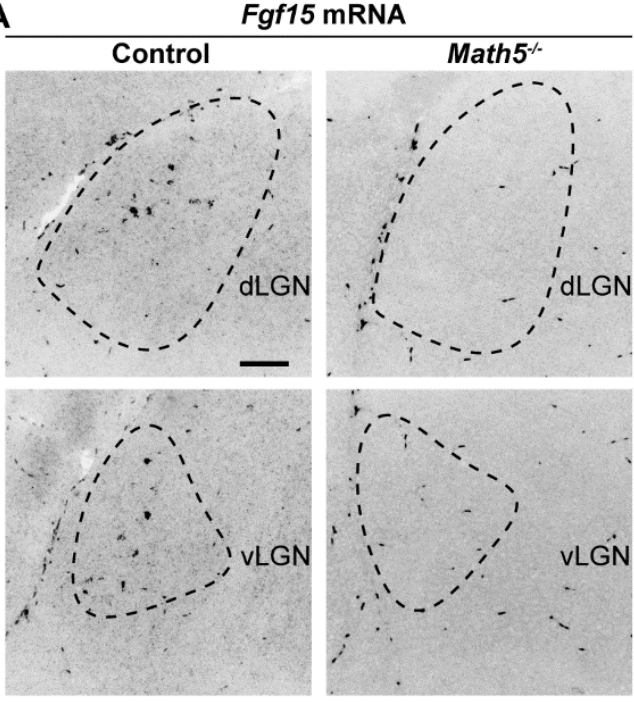

B

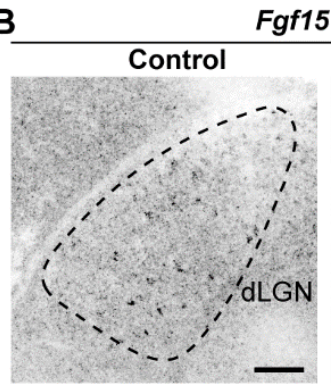

Fgf15 mRNA

$\mathrm{Shh}^{\text {flth }} ; \mathrm{Nes}^{\mathrm{Cre}}$

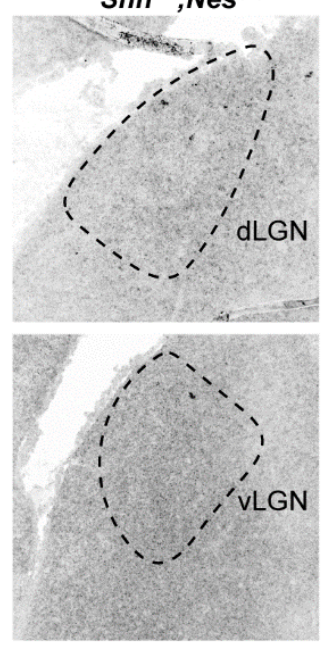

C

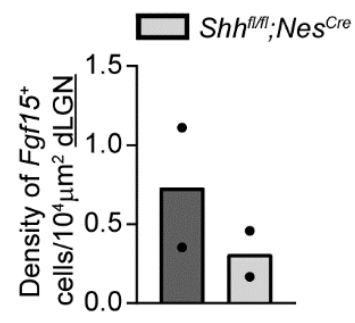

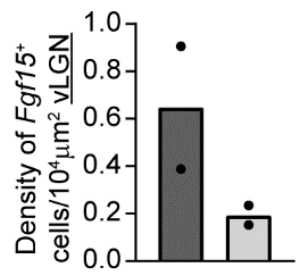




\section{Figure S2. Thalamic Fgf15 expression is dependent on retinal inputs and SHH}

(A) ISH revealed a dramatic reduction in Fgf15 expression in dLGN and vLGN of P2 Math5\% mutants compared with controls.

(B) ISH revealed a dramatic reduction in Fgf15 expression in dLGN and vLGN of P3 Shh ${ }^{f / f I} \mathrm{Nes}^{\mathrm{Cre}}$ mutants compared with controls.

(C) Quantification for density of Fgf15+ cells in dLGN and vLGN of P3 control and Shh ${ }^{f / f /} \mathrm{Nes}^{\mathrm{Cre}}$ mutant mice. Each data point represents one biological replicate and bars depict means \pm SEM ( $n=2$ mice for each group).

Scale bars in A, B: $100 \mu \mathrm{m}$. 


\section{REFERENCES}

Ahn, S., and Joyner, A.L. (2005). In vivo analysis of quiescent adult neural stem cells responding to Sonic hedgehog. Nature 437, 894-897.

Arcelli, P., Frassoni, C., Regondi, M.C., Biasi, S. De, and Spreafico, R. (1997). GABAergic neurons in mammalian thalamus: A marker of thalamic complexity? Brain Res. Bull. 42, 27-37.

Belgacem, Y.H., Hamilton, A.M., Shim, S., Spencer, K.A., and Borodinsky, L.N. (2016). The Many Hats of Sonic Hedgehog Signaling in Nervous System Development and Disease. J. Dev. Biol. 4.

Bickford, M.E., Slusarczyk, A., Dilger, E.K., Krahe, T.E., Kucuk, C., and Guido, W. (2010). Synaptic development of the mouse dorsal lateral geniculate nucleus. J. Comp. Neurol. 518, 622-635.

Brooks, J.M., Su, J., Levy, C., Wang, J.S., Seabrook, T.A., Guido, W., and Fox, M.A. (2013). A molecular mechanism regulating the timing of corticogeniculate innervation. Cell Rep. 5, 573-581.

C. Brunjes, P. (1994). Unilateral naris closure and olfactory system development. Brain Res. Rev. 19, 146-160.

Charalambakis, N.E., Govindaiah, G., Campbell, P.W., and Guido, W. (2019). Developmental remodeling of thalamic interneurons requires retinal signaling. J. Neurosci. 39, 3856-3866.

Chiang, C., Litingtung, Y., Lee, E., Young, K.E., Corden, J.L., Westphal, H., and Beachy, P.A. (1996). Cyclopia and defective axial patterning in mice lacking Sonic hedgehog gene function. Nature 383, 407-413.

Ciftcioglu, U.M., Suresh, V., Ding, K.R., Sommer, F.T., and Hirsch, J.A. (2020). Visual Information Processing in the Ventral Division of the Mouse Lateral Geniculate Nucleus of the Thalamus. J. Neurosci. 40, 5019-5032.

Crombie, D., and Busse, L. (2021). Should I stay or should I go? A thalamic circuit for modulating behavioral responses to visual threat. Neuron 109, 3717-3719.

D'Souza, S., and Lang, R.A. (2020). Retinal ganglion cell interactions shape the developing mammalian visual system. Development 147, 1-13.

Dakubo, G.D., Beug, S.T., Mazerolle, C.J., Thurig, S., Wang, Y., and Wallace, V.A. (2008). Control of glial precursor cell development in the mouse optic nerve by sonic hedgehog from retinal ganglion cells. Brain Res. 1228, 27-42.

Evangelio, M., García-Amado, M., and Clascá, F. (2018). Thalamocortical projection neuron and interneuron numbers in the visual thalamic nuclei of the adult C57BL/6 mouse. Front. Neuroanat. 12, 1-12.

Farmer, W.T., Abrahamsson, T., Chierzi, S., Lui, C., Zaelzer, C., Jones, E. V., Bally, B.P., Chen, G.G., Théroux, J.F., Peng, J., et al. (2016). Neurons diversify astrocytes in the adult brain through sonic hedgehog signaling. Science (80-. ). 351, 849854.

Fratzl, A., Koltchev, A.M., Vissers, N., Tan, Y.L., Marques-Smith, A., Stempel, A.V., Branco, T., and Hofer, S.B. (2021). Flexible inhibitory control of visually evoked defensive behavior by the ventral lateral geniculate nucleus. Neuron 109, 38103822.e9.

Garcia, A.D.R., Petrova, R., Eng, L., and Joyner, A.L. (2010). Sonic Hedgehog regulates discrete populations of astrocytes in the adult mouse forebrain. J. Neurosci. 30, 13597-13608.

Garcia, A.D.R., Han, Y.G., Triplett, J.W., Farmer, W.T., Harwell, C.C., and Ihrie, R.A. (2018). The elegance of sonic hedgehog: Emerging novel functions for a classic morphogen. J. Neurosci. 38, 9338-9345.

Golding, B., Pouchelon, G., Bellone, C., Murthy, S., Di Nardo, A.A., Govindan, S., Ogawa, M., Shimogori, T., Lüscher, C., Dayer, A., et al. (2014). Retinal input directs the recruitment of inhibitory interneurons into thalamic visual circuits. Neuron 81, 1057-1069.

Grant, E., Hoerder-Suabedissen, A., and Molnar, Z. (2016). The Regulation of Corticofugal Fiber Targeting by Retinal Inputs. Cereb. Cortex 26, 1336-1348. 
Guido, W. (2018). Development, form, and function of the mouse visual thalamus. J. Neurophysiol. 120, 211-225.

Harrington, M.E. (1997). The VentralLateralGeniculateNucleusandthe Intergeniculate Leaflet:IntenelatedStructures in the Visual andCircadianSystems. Neurosci. AndBiobehavioral Rev. 21, 705-727.

He, J., Xu, X., Monavarfeshani, A., Banerjee, S., Fox, M.A., and Xie, H. (2019). Retinal-input-induced epigenetic dynamics in the developing mouse dorsal lateral geniculate nucleus. Epigenetics and Chromatin 12, 1-16.

Hill, S.A., Blaeser, A.S., Coley, A.A., Xie, Y., Shepard, K.A., Harwell, C.C., Gao, W.-J., and Garcia, A.D.R. (2019). Sonic hedgehog signaling in astrocytes mediates cell type-specific synaptic organization. Elife 8, 1-23.

Van Horn, S.C., Erişir, A., and Sherman, S.M. (2000). Relative distribution of synapses in the A-laminae of the lateral geniculate nucleus of the cat. J. Comp. Neurol. 416, 509.

Huang, L., Xi, Y., Peng, Y., Yang, Y., Huang, X., Fu, Y., Tao, Q., Xiao, J., Yuan, T., An, K., et al. (2019). A Visual Circuit Related to Habenula Underlies the Antidepressive Effects of Light Therapy. Neuron 102, 128-142.e8.

Huberman, A.D., Wang, G.Y., Liets, L.C., Collins, O.A., Chapman, B., and Chalupa, L.M. (2003). Eye-specific retinogenicu late segregation independent of normal neuronal activity. Science (80-. ). 300, 994-998.

Huberman, A.D., Feller, M.B., and Chapman, B. (2008). Mechanisms underlying development of visual maps and receptive fields. Annu. Rev. Neurosci. 31, 479-509.

Ihrie, R.A., Shah, J.K., Harwell, C.C., Levine, J.H., Guinto, C.D., Lezameta, M., Kriegstein, A.R., and Alvarez-Buylla, A. (2011). Persistent Sonic Hedgehog Signaling in Adult Brain Determines Neural Stem Cell Positional Identity. Neuron 71, 250-262.

Ishibashi, M., and McMahon, A.P. (2002a). A sonic hedgehog-dependent signaling relay regulates growth of diencephalic and mesencephalic primordia in the early mouse embryo. Development 129, 4807-4819.

Ishibashi, M., and McMahon, A.P. (2002b). A sonic hedgehog-dependent signaling relay regulates growth of diencephalic and mesencephalic primordia in the early mouse embryo. Development 129, 4807-4819.

Jager, P., Ye, Z., Yu, X., Zagoraiou, L., Prekop, H.T., Partanen, J., Jessell, T.M., Wisden, W., Brickley, S.G., and Delogu, A. (2016). Tectal-derived interneurons contribute to phasic and tonic inhibition in the visual thalamus. Nat. Commun. 7, 114.

Jager, P., Moore, G., Calpin, P., Durmishi, X., Salgarella, I., Menage, L., Kita, Y., Wang, Y., Kim, D.W., Blackshaw, S., et al. (2021). Dual midbrain and forebrain origins of thalamic inhibitory interneurons. Elife 10, 1-29.

Jaubert-Miazza, L., Green, E., Lo, F.S., Bui, K., Mills, J., and Guido, W. (2005). Structural and functional composition of the developing retinogeniculate pathway in the mouse. Vis. Neurosci. 22, 661-676.

Jensen, A.M., and Wallace, V.A. (1997). Expression of Sonic hedgehog and its putative role as a precursor cell mitogen in the developing mouse retina. Development 124, 363-371.

Katz, L.C., and Shatz, C.J. (1996). Synaptic Activity and the Construction of Cortical Circuits. Science (80-. ). 274, 11331138.

Kerr, A., Patel, P.A., LaConte, L.E.W., Liang, C., Chen, C.K., Shah, V., Fox, M.A., and Mukherjee, K. (2019). Non-Cell Autonomous Roles for CASK in Optic Nerve Hypoplasia. Invest. Ophthalmol. Vis. Sci. 60, 3584-3594.

Kim, J.J., Jiwani, T., Erwood, S., Loree, J., and Rosenblum, N.D. (2018). Suppressor of fused controls cerebellar neuronal differentiation in a manner modulated by GLI3 repressor and Fgf15. Dev. Dyn. 247, 156-169.

Koehler, C.C., Hall, L.M., Hellmer, C.B., and Ichinose, T. (2019). Using looming visual stimuli to evaluate mouse vision. J. Vis. Exp. 2019, 100-106.

Komada, M., Saitsu, H., Kinboshi, M., Miura, T., Shiota, K., and Ishibashi, M. (2008a). Hedgehog signaling is involved in development of the neocortex. Development 135, 2717-2727. 
Komada, M., Saitsu, H., Shiota, K., and Ishibashi, M. (2008b). Expression of Fgf15 is regulated by both activator and repressor forms of Gli2 in vitro. Biochem. Biophys. Res. Commun. 369, 350-356.

Krahe, T.E., El-Danaf, R.N., Dilger, E.K., Henderson, S.C., and Guido, W. (2011). Morphologically distinct classes of relay cells exhibit regional preferences in the dorsal lateral geniculate nucleus of the mouse. J. Neurosci. 31, 17437-17448.

Leist, M., Datunashvilli, M., Kanyshkova, T., Zobeiri, M., Aissaoui, A., Cerina, M., Romanelli, M.N., Pape, H.C., and Budde, T. (2016). Two types of interneurons in the mouse lateral geniculate nucleus are characterized by different $h$-current density. Sci. Rep. 6, 1-15.

Lendahl, U., Zimmerman, L.B., and McKay, R.D.G. (1990). CNS stem cells express a new class of intermediate filament protein. Cell 60, 585-595.

Link, E., Edelmann, L., Chou, J.H., Binz, T., Yamasaki, S., Eisel, U., Baumert, M., Südhof, T.C., Niemann, H., and Jahn, R. (1992). Tetanus toxin action: Inhibition of neurotransmitter release linked to synaptobrevin proteolysis. Biochem. Biophys. Res. Commun. 189, 1017-1023.

Machold, R., Hayashi, S., Rutlin, M., Muzumdar, M.D., Nery, S., Corbin, J.G., Gritli-Linde, A., Dellovade, T., Porter, J.A., Rubin, L.L., et al. (2003). Sonic hedgehog is required for progenitor cell maintenance in telencephalic stem cell niches. Neuron 39, 937-950.

Marigo, V., Laufer, E., Nelson, C.E., Riddle, R.D., Johnson, R.L., and Tabin, C. (1996). Sonic hedgehog regulates patterning in early embryos. Biochem. Soc. Symp. 62, 51-60.

Martinez-Ferre, A., Lloret-Quesada, C., Prakash, N., Wurst, W., Rubenstein, J.L.R., and Martinez, S. (2016). Fgf15 regulates thalamic development by controlling the expression of proneural genes. Brain Struct. Funct. 221, 3095-3109.

Monavarfeshani, A., Sabbagh, U., and Fox, M.A. (2017). Not a one-trick pony: Diverse connectivity and functions of the rodent lateral geniculate complex. Vis. Neurosci. 34, E012.

Monavarfeshani, A., Stanton, G., Van Name, J., Su, K., Mills, W.A., Swilling, K., Kerr, A., Huebschman, N.A., Su, J., and Fox, M.A. (2018). LRRTM1 underlies synaptic convergence in visual thalamus. Elife 7, 1-24.

Nithianantharajah, J., and Hannan, A.J. (2006). Enriched environments, experience-dependent plasticity and disorders of the nervous system. Nat. Rev. Neurosci. 7, 697-709.

Ornitz, D.M., and Itoh, N. (2015). The fibroblast growth factor signaling pathway. Wiley Interdiscip. Rev. Dev. Biol. 4, 215266.

Peng, J., Fabre, P.J., Dolique, T., Swikert, S.M., Kermasson, L., Shimogori, T., and Charron, F. (2018a). Sonic Hedgehog Is a Remotely Produced Cue that Controls Axon Guidance Trans-axonally at a Midline Choice Point. Neuron 97, 326340.e4.

Peng, J., Fabre, P.J., Dolique, T., Swikert, S.M., Kermasson, L., Shimogori, T., and Charron, F. (2018b). Sonic Hedgehog Is a Remotely Produced Cue that Controls Axon Guidance Trans-axonally at a Midline Choice Point. Neuron 97, 326340.e4.

Pfeiffenberger, C., Cutforth, T., Woods, G., Yamada, J., Rentería, R.C., Copenhagen, D.R., Flanagan, J.G., and Feldheim, D.A. (2005). Ephrin-As and neural activity are required for eye-specific patterning during retinogeniculate mapping. Nat. Neurosci. 8, 1022-1027.

Rallu, M., Machold, R., Gaiano, N., Corbin, J.G., McMahon, A.P., and Fishell, G. (2002). Dorsoventral patterning is established in the telencephalon of mutants lacking both Gli3 and hedgehog signaling. Development 129, $4963-4974$.

Rheaume, B.A., Jereen, A., Bolisetty, M., Sajid, M.S., Yang, Y., Renna, K., Sun, L., Robson, P., and Trakhtenberg, E.F. (2018). Single cell transcriptome profiling of retinal ganglion cells identifies cellular subtypes. Nat. Commun. 9.

Sabbagh, U., Monavarfeshani, A., Su, K., Zabet-Moghadam, M., Cole, J., Carnival, E., Su, J., Mirzaei, M., Gupta, V., Salekdeh, G.H., et al. (2018). Distribution and development of molecularly distinct perineuronal nets in visual thalamus. J. 
Neurochem. 147, 626-646.

Sabbagh, U., Govindaiah, G., Somaiya, R.D., Ha, R. V., Wei, J.C., Guido, W., and Fox, M.A. (2021). Diverse GABAergic neurons organize into subtype-specific sublaminae in the ventral lateral geniculate nucleus. J. Neurochem. 159, $479-497$.

Saitsu, H., Komada, M., Suzuki, M., Nakayama, R., Motoyama, J., Shiota, K., and Ishibashi, M. (2005). Expression of the mouse Fgf15 gene is directly initiated by Sonic hedgehog signaling in the diencephalon and midbrain. Dev. Dyn. 232, 282292.

Salay, L.D., and Huberman, A.D. (2021). Divergent outputs of the ventral lateral geniculate nucleus mediate visually evoked defensive behaviors. Cell Rep. 37, 109792.

Sando, R., Bushong, E., Zhu, Y., Huang, M., Considine, C., Phan, S., Ju, S., Uytiepo, M., Ellisman, M., and Maximov, A. (2017). Assembly of Excitatory Synapses in the Absence of Glutamatergic Neurotransmission. Neuron 94, 312-321.e3.

Sanes, J.R., and Lichtman, J.W. (2001). Induction, assembly, maturation and maintenance of a postsynaptic apparatus. Nat. Rev. Neurosci. 2, 791-805.

Schmittgen, T.D., and Livak, K.J. (2008). Analyzing real-time PCR data by the comparative CT method. Nat. Protoc. 3, 1101-1108.

Schoch, S., Deák, F., Königstorfer, A., Mozhayeva, M., Sara, Y., Südhof, T.C., and Kavalali, E.T. (2001). SNARE function analyzed in synaptobrevin/VAMP knockout mice. Science (80-. ). 294, 1117-1122.

Seabrook, T.A., El-Danaf, R.N., Krahe, T.E., Fox, M.A., and Guido, W. (2013). Retinal input regulates the timing of corticogeniculate innervation. J. Neurosci. 33, 10085-10097.

Sherman, S.M., and Guillery, R.W. (2002). The role of the thalamus in the flow of information to the cortex. Philos. Trans. R. Soc. B Biol. Sci. 357, 1695-1708.

Somaiya, R.D., Huebschman, N.A., Chaunsali, L., Sabbagh, U., Carrillo, G.L., Tewari, B.P., and Fox, M.A. (2021). Development of astrocyte morphology and function in mouse visual thalamus. J. Comp. Neurol. 1-18.

Su, J., Gorse, K., Ramirez, F., and Fox, M.A. (2010). Collagen XIX is expressed by interneurons and contributes to the formation of hippocampal synapses. J. Comp. Neurol. 518, 229-253.

Su, J., Haner, C. V., Imbery, T.E., Brooks, J.M., Morhardt, D.R., Gorse, K., Guido, W., and Fox, M.A. (2011). Reelin is required for class-specific retinogeniculate targeting. J. Neurosci. 31, 575-586.

Su, J., Charalambakis, N.E., Sabbagh, U., Somaiya, R.D., Monavarfeshani, A., Guido, W., and Fox, M.A. (2020). Retinal inputs signal astrocytes to recruit interneurons into visual thalamus. Proc. Natl. Acad. Sci. U. S. A. 117, 2671-2682.

Su, J., Sabbagh, U., Liang, Y., Olejnıkova, L., Dixon, K.G., Russell, A.L., Chen, J., Pan, Y.A., Triplett, J.W., and Fox, M.A. (2021). A cell-ECM mechanism for connecting the ipsilateral eye to the brain. Proc. Natl. Acad. Sci. U. S. A. 118, 1-12.

Su, Y., Yuan, Y., Feng, S., Ma, S., and Wang, Y. (2017). High frequency stimulation induces sonic hedgehog release from hippocampal neurons. Sci. Rep. 7, 1-13.

Tirou, L., Russo, M., Faure, H., Pellegrino, G., Demongin, C., Daynac, M., Sharif, A., Amosse, J., Le Lay, S., Denis, R., et al. (2021). Sonic Hedgehog receptor Patched deficiency in astrocytes enhances glucose metabolism in mice. Mol. Metab. 47, 101172.

Traiffort, E., Moya, K.L., Faure, H., Hässig, R., and Ruat, M. (2001). High expression and anterograde axonal transport of aminoterminal sonic hedgehog in the adult hamster brain. Eur. J. Neurosci. 14, 839-850.

Tran, N.M., Shekhar, K., Whitney, I.E., Jacobi, A., Benhar, I., Hong, G., Yan, W., Adiconis, X., Arnold, M.E., Lee, J.M., et al. (2019). Single-Cell Profiles of Retinal Ganglion Cells Differing in Resilience to Injury Reveal Neuroprotective Genes. Neuron 104, 1039-1055.e12.

Tronche, F., Kellendonk, C., Kretz, O., Gass, P., Anlag, K., Orban, P.C., Bock, R., Klein, R., and Schütz, G. (1999). 
Disruption of the glucocorticoid receptor gene in the nervous system results in reduced anxiety. Nat. Genet. 23, 99-103.

Ugbode, C.I., Smith, I., Whalley, B.J., Hirst, W.D., and Rattray, M. (2017). Sonic hedgehog signalling mediates astrocyte crosstalk with neurons to confer neuroprotection. J. Neurochem. 142, 429-443.

Wallace, V.A., and Raff, M.C. (1999). A role for Sonic hedgehog in axon-to-astrocyte signalling in the rodent optic nerve. Development 126, 2901-2909.

Wang, Y., Dakubo, G.D., Thurig, S., Mazerolle, C.J., and Wallace, V.A. (2005). Retinal ganglion cell-derived sonic hedgehog locally controls proliferation and the timing of RGC development in the embryonic mouse retina. Development 132, 51035113.

Xu, Q., Wonders, C.P., and Anderson, S.A. (2005). Sonic hedgehog maintains the identity of cortical interneuron progenitors in the ventral telencephalon. Development 132, 4987-4998.

Yabut, O.R., Ng, H.X., Yoon, K., Gomez, H.G., Arela, J.C., and Pleasure, S.J. (2019). Combined modulation of SHH and FGF signaling is crucial for maintenance of the neocortical progenitor specification program. BioRxiv 40, 6872-6887.

Yuge, K., Kataoka, A., Yoshida, A.C., Itoh, D., Aggarwal, M., Mori, S., Blackshaw, S., and Shimogori, T. (2011). Regionspecific gene expression in early postnatal mouse thalamus. J. Comp. Neurol. 519, 544-561.

Zhang, Y., Narayan, S., Geiman, E., Lanuza, G.M., Velasquez, T., Shanks, B., Akay, T., Dyck, J., Pearson, K., Gosgnach, S., et al. (2008). V3 Spinal Neurons Establish a Robust and Balanced Locomotor Rhythm during Walking. Neuron 60, 8496.

Zimmerman, L., Lendahl, U., Cunningham, M., McKay, R., Parr, B., Gavin, B., Mann, J., Vassileva, G., and McMahon, A. (1994). Independent regulatory elements in the nestin gene direct transgene expression to neural stem cells or muscle precursors. Neuron 12, 11-24. 


\section{A}

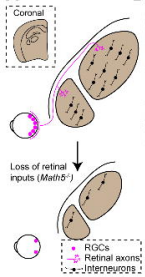

B

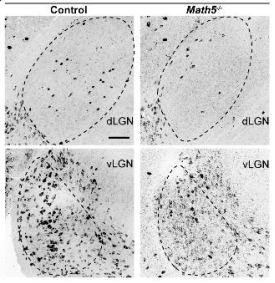

C $\square$ Control
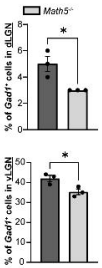

D E

R26 promoter

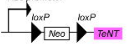

\section{$\mathrm{X}$}

ATO-Colb2- ires- $\mathrm{Cro}$
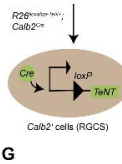

Cab2' cells (RECS)

G

Sfit gene

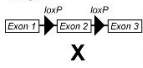

Motin pronotor \& onhancer $\rightarrow$

Cre $\mathrm{hGH} \mathrm{pA}$

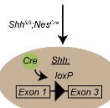

Nos colle ineuronal and glia precursora?

$\mathrm{H}$
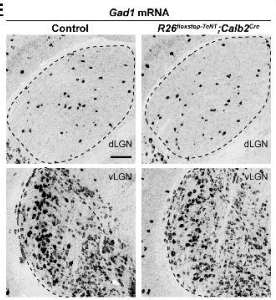

F
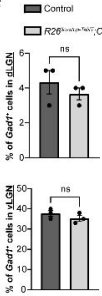

Control Gady mRNA
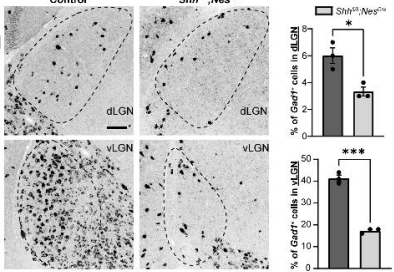
A

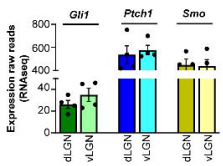

B

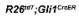

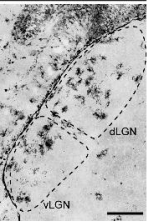

C
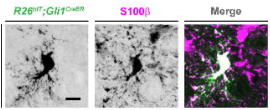

D

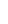
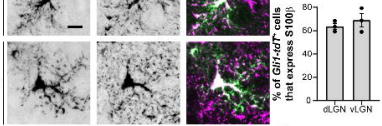

E

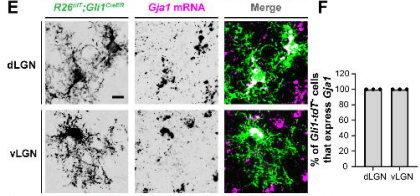

G
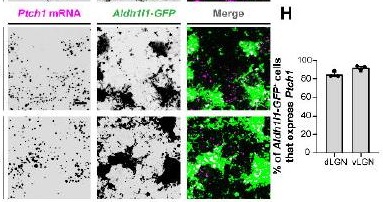

I
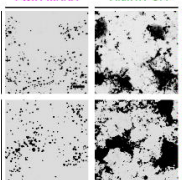

6\%, , , ,

Smo mRNA Aldirlis.GFP

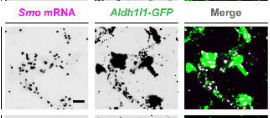

$\mathrm{J}$

dL 
A
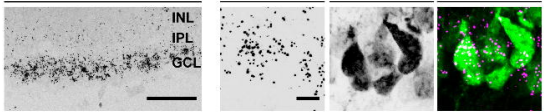

C

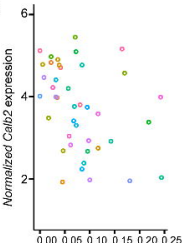

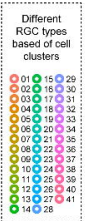

Normalized Shh expression
D

$\square$ Control

$\square \operatorname{Shn}: \operatorname{Can} 2 \%$

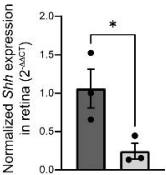

E

Fgf15 mRNA

$\mathbf{F}$

$\square$ Control

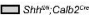

Control
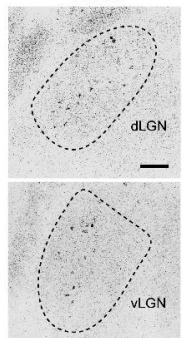

$\mathrm{Sh}^{\text {ilf }} ; \mathrm{Calb2} 2^{\mathrm{Cro}}$
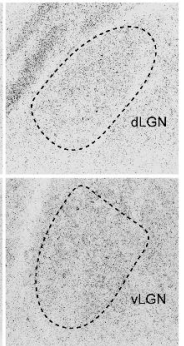
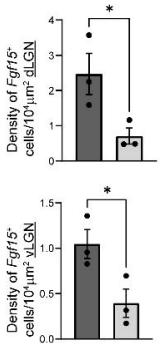


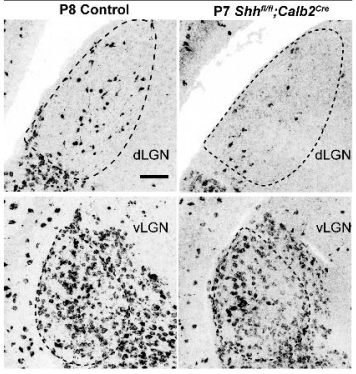

C

\section{Gad1 mRNA}
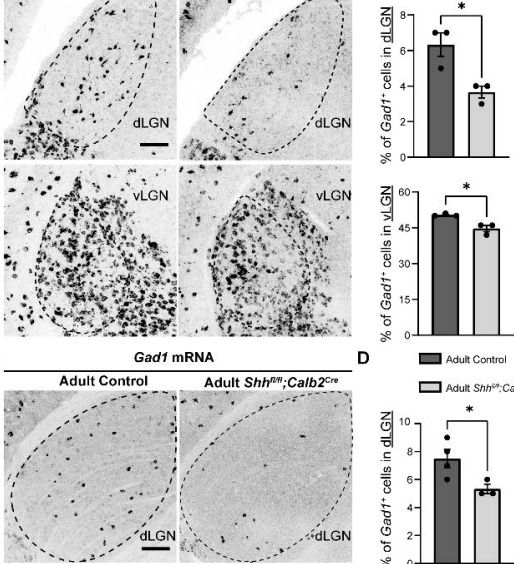

\section{Adult $S h h^{\text {nit }} ; C_{a}$ alb2 $2^{\text {cro }}$}

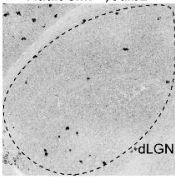

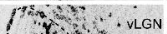

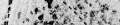

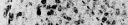

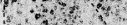

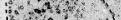

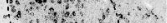

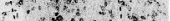

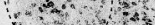

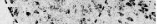

$\Rightarrow \quad \because 464.05 \%$

$\because 4 \theta^{2}, v^{2} v^{2}$
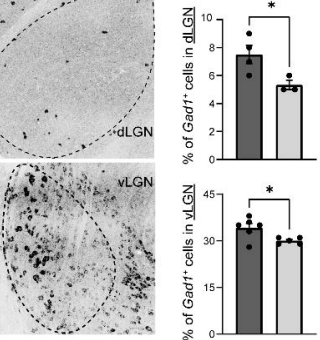